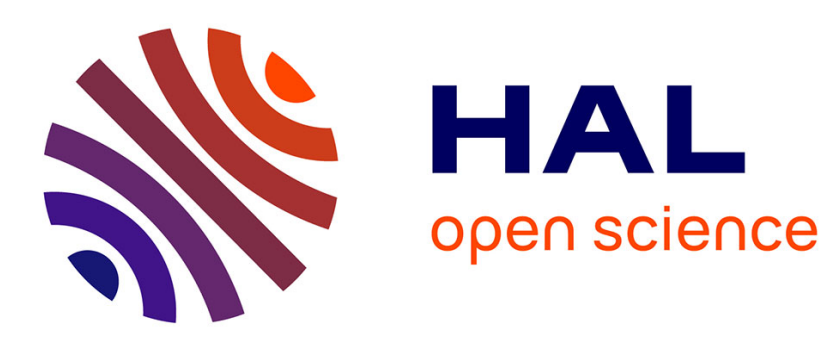

\title{
Habit Formation and Fiscal Transmission in Open Economies
}

\author{
Olivier Cardi, Gernot J. Muller
}

\section{To cite this version:}

Olivier Cardi, Gernot J. Muller. Habit Formation and Fiscal Transmission in Open Economies. 2010. hal-00544484

\section{HAL Id: hal-00544484 \\ https://hal.science/hal-00544484}

Preprint submitted on 8 Dec 2010

HAL is a multi-disciplinary open access archive for the deposit and dissemination of scientific research documents, whether they are published or not. The documents may come from teaching and research institutions in France or abroad, or from public or private research centers.
L'archive ouverte pluridisciplinaire HAL, est destinée au dépôt et à la diffusion de documents scientifiques de niveau recherche, publiés ou non, émanant des établissements d'enseignement et de recherche français ou étrangers, des laboratoires publics ou privés. 


\title{
ECOLE POLYTECHNIQUE
}

CENTRE NATIONAL DE LA RECHERCHE SCIENTIFIQUE

\section{HABIT FORMATION AND FISCAL TRANSMISSION IN OPEN ECONOMIES}

\author{
Olivier CARDI \\ Gernot J. MULLER
}

December, 2010

Cahier n $^{\circ}$ 2010-32

\section{DEPARTEMENT D'ECONOMIE}

Route de Saclay

91128 PALAISEAU CEDEX

(33) 169333033

http://www.enseignement.polytechnique.fr/economie/

mailto:chantal.poujouly@polytechnique.edu 


\title{
HABIT FORMATION AND FISCAL TRANSMISSION IN OPEN ECONOMIES*
}

\author{
Olivier CARDI \\ Université Panthéon-Assas ERMES \\ Gernot J. MÜLLER \\ Ecole Polytechnique
}

\begin{abstract}
In this paper we analyze the ability of an open economy version of the neoclassical model to account for the time-series evidence on fiscal policy transmission. In a first step, we identify government spending shocks within a vector autoregression model. We find that i) government spending increases output and induces a simultaneous decline of investment and the current account, but does not affect consumption; ii) the responses of output and investment are smaller in more open economies, while current account deficits tend to be larger. We find the predictions of the model to be broadly in line with the evidence, once we allow for habit formation in consumption. Specifically, habits are crucial for government spending to induce a simultaneous decline in investment and the current account.
\end{abstract}

Keywords: Investment; Current Account; Habit Formation; Fiscal Policy.

JEL Classification: F41; E32; E62.

Constructive comments by Luisito Bertinelli, Peter Claeys, Romain Restout, Stefan Schubert, Partha Sen, Eric Strobl are gratefully acknowledged. An earlier version of this paper was presented to the 12 th Conference Theories and Methods of Macroeconomics, 17-18th January 2008, ERMES seminar, 10th April 2008, 14th Conference on Computing in Economics and Finance, 26-28th June 2008, 57th Congress of Association Française de Science Economique, 18-19th September 2008, Ecole Polytechnique lunch seminar, 12th April 2010, 25th Meeting of the European Economic Association, 23-26th August 2010, and has benefited from helpful comments of participants. Of course the usual disclaimers apply. Address correspondence: Olivier Cardi, Université Panthéon-Assas Paris 2, ERMES, 12 Place du Panthéon, 75230 Paris Cedex 05. France. Phone: +33 1444189 64. Fax: +33 140 5181 30. E-mail: olivier.cardi@u-paris2.fr. Address correspondence: Gernot Müller, Department of Economics, University of Bonn, Lennéstr. 37, 53113 Bonn, Germany. E-mail: gernot.mueller@uni-bonn.de. 


\section{Introduction}

Interest in specific aspects of the fiscal transmission mechanism has grown recently, both among policy makers and within the academic literature. A number of studies have applied different identification schemes to establish time-series evidence on the effects of fiscal shocks, see, e.g., Blanchard and Perotti [2002], Mountford and Uhlig [2009], and Ramey [2010]. Others have explored the ability of quantitative business cycle models, both of the neoclassical and of the new Keynesian variety, to account for the evidence, see Burnside, Eichenbaum and Fisher [2004] and Gali, Lopez-Salido and Valles [2007], respectively. Most of the analyses have been confined to closed economy models, however. In the present paper we take up the following question instead: to what extent can an open economy version of the neoclassical model account for the time-series evidence on fiscal policy transmission?

In order to establish evidence on the fiscal transmission mechanism we estimate a vector autoregression (VAR) model on quarterly time-series data for the U.S., Australia, U.K, and Canada covering the period 1980-2007. We identify government spending shocks under the assumption that government spending is predetermined relative to the other variables included in the VAR model, as suggested by Blanchard and Perotti [2002]. Two findings emerge. First, an exogenous increase in government spending has virtually no effect on private consumption, raises output, and lowers both investment and the current account. Second, we find that the decline of investment is less pronounced in those economies of our sample which are more open to trade. At the same time, the current account deficit tends to be larger and the effects on output more muted in more open economies. By and large, these findings are in line with evidence documented elsewhere. ${ }^{1}$

We put forward a variant of the neoclassical model and assess its ability to account for these findings. Specifically, we focus on a semi-small open economy model. As in Buiter [1987], the economy is small in world capital markets so that the world interest rate is given, but large enough in the world good market to influence the relative price of the domestic good, i.e. the terms of trade. Importantly, we also allow for the possibility that preferences are not timeseparable but characterized by habit forming behavior, as in, e. g. , Campbell and Cochrane [1999] and Carrol et al. [2000].

\footnotetext{
${ }^{1}$ Studies based on the Blanchard-Perotti identification scheme typically report a positive consumption response to an exogenous increase in government spending. More recent evidence based on this approach, however, suggests a decline in the consumption response, see Perotti [2005]. Studies based on alternative identification schemes report a small decline of consumption or no significant response, see Ramey [2010] and Mountford and Uhlig [2009], respectively. A number of studies find that government spending reduces the current account, e.g., Corsetti and Müller [2006], Beetsma, Giuliodori and Klaassen [2008], Monacelli and Perotti [2006]. Kim and Roubini [2008] instead find a positive effect for the US.
} 
Assuming time-separable preferences, we find that the model generally fails to account for the first set of observations, notably for the simultaneous decline of investment and the current account in response to an exogenous and temporary increase in government spending. To understand this result, consider first a relatively long-lived increase in spending which implies a sizeable drain on the resources available to the private sector. As stressed in the classic paper by Baxter and King [1993], a representative household responds to the higher tax burden (which we assume to be lump-sum in the baseline scenario) by lowering consumption and increasing labor supply. This raises the return on capital and triggers a rise of investment, which, in turn, drives the current account into deficit. At the same time, the increase of government spending on domestic goods appreciates the terms of trade and raises the rate of return on foreign bonds. Investment will therefore decrease whenever the spending shock is short-lived, as the rise of labor supply and, hence, of the return on capital is small in this case. However, the current account fails to decline, as the fall in savings does not exceed the drop in investment. ${ }^{2}$

The ability of the model to account for the evidence improves, however, once we allow for habit formation. Two factors are crucial. First, while habit-forming agents also reduce consumption in response to the spending shock, they find it optimal to do so only moderately and, hence, savings decrease more than in the case of time-separable preferences. Second, under habits, household's labor supply also increases less for any given duration of the expansionary fiscal policy, because the marginal utility of wealth rises less in this case. We thus obtain a simultaneous decline of investment and the current account, once we allow for habit formation.

Regarding our second set of findings, which concerns the role of trade openness, we also find the performance of the model increased, once we allow for habits. It is only in this case that we find current accounts deficits to increase in openness. We show, however, that the output effects of spending shocks decline in openness under both preference specifications. This finding seems particularly noteworthy, because Perotti [2005] documents smaller output effects of spending shocks in a post-1980 sample relative to results for the pre-1980 period. Since the countries in his sample have become more open over time, this trend may be partly responsible for the reduced output effects of government spending.

Closely related to our paper is the study by Karayalçin [1999] who simulates a small open economy model and finds that a temporary fiscal impulse stimulates capital accumulation and induces a current account deficit. ${ }^{3}$ Karayalçin [2003] also allows for time non-separable

\footnotetext{
${ }^{2}$ For an earlier analytical study of long-lived temporary fiscal expansion, see Turnovsky and Sen [1991] who consider a semi-small open economy model with time-separable preferences.

${ }^{3}$ In a small open economy model, since the return on foreign assets is fixed as the terms of trade are exogenous, higher labor supply always pushes up the return on domestic and capital. Hence, a fiscal shock always crowds-in investment in such a framework.
} 
preferences and analyzes the effects of a permanent public spending shock in an open economy model. Yet, while we introduce the habit index into instantaneous utility, Karayalçin uses recursive preferences and introduces the stock of habits into the subjective time discount rate. Under this specification the model predicts a current account surplus. ${ }^{4}$

The remainder of the paper is organized as follows. In section 2, we present VAR evidence on the macroeconomic effects of government spending shocks. In section 3, we develop an open economy version of the neoclassical model with habit formation. Section 4 provides an analytical exploration on the role of habits for the transmission of fiscal shocks. In section 5 , we report results from numerical simulations and discuss the role of trade openness. In section 6 , we report results from sensitivity analysis. Section 7 summarizes our main results and concludes.

\section{Time-series evidence on the effects of fiscal shocks}

In this section we establish time-series evidence on the effects of government spending shocks on the basis of an estimated vector autoregression (VAR) model. We briefly discuss the specification of our VAR model and the data before we present results.

\subsection{Specification of VAR model}

We estimate a VAR model on quarterly time-series data, allowing for four lags of the vector of endogenous variables, $y_{t}$. We also include a constant and a linear time trend, which we omit from the following representation of the structural model:

$$
A_{0} y_{t}=A_{1} y_{t-1}+A_{2} y_{t-2}+A_{3} y_{t-3}+A_{4} y_{t-4}+\varepsilon_{t}
$$

Here $A_{i}, i \in\{0,1,2,3,4\}$ are appropriately defined coefficient matrices and $\varepsilon_{t}$ are structural innovations for which we assume $E \varepsilon_{t} \varepsilon_{t}^{\prime}=I$.

In our baseline specification $y_{t}$ includes, in logs and real terms: government consumption, taxes net of transfers, GDP, private non-residential investment as well as the current account in percent of GDP and short-term nominal interest rate. We also estimate a second model where we replace investment with private consumption expenditures in order to economize on the degrees of freedom. We consider the sample period 1980Q1-2007Q4, as Perotti [2005] shows that there has been a change in the fiscal transmission mechanism after 1980.

\footnotetext{
${ }^{4}$ Related studies include Corsetti and Müller [2006] and Müller [2008] who consider two-country business cycle models and investigate how their predictions relate to time-series evidence on the fiscal transmission mechanism. In contrast to these studies we consider a semi-small open economy model and a continuous-time framework which allows us to establish a number of analytical results.
} 
We are exclusively interested in the effects of government spending on the other variables included in $y_{t}$. In order to identify exogenous innovations in government spending, we follow Blanchard and Perotti [2002] and assume that government spending is predetermined relative to the other variables included in the VAR model. ${ }^{5}$ This assumption appears not too restrictive, as government spending does not include transfers (such as unemployment benefits) and is therefore unlikely to respond automatically to the other variables. In addition, decision lags are likely to prevent policy makers to respond within the quarter in a discretionary and systematic manner to the state of the economy. As government spending is ordered first within $y_{t}$, the first element of $\varepsilon_{t}$ represents a government spending shock under our identification assumption, i.e., an exogenous innovation, the effect of which on the other variables we seek to quantify. We do not provide a structural interpretation of innovations other than those to government spending and thus assume, by way of normalization, that $A_{0}$ is lower-triangular, see Christiano et al. [1999]. We estimate the VAR model (1) recursively by OLS.

\subsection{Data}

We consider data for the following countries: Canada, Australia, the UK and the US. VAR studies of the fiscal transmission mechanism have traditionally been limited to those four countries, because of the limited availability of non-interpolated quarterly fiscal data, see Perotti [2005].

All data are obtained from the OECD Economic outlook database. Government spending is government final consumption expenditure (value, appropriation account) deflated with the GDP deflator. ${ }^{6}$ Taxes net of transfers are receipts (Current receipts, general government value) less subsidies (value) and social security benefits paid by general government (value), deflated with the GDP deflator. For private consumption and investment, we directly consider the volumes reported by the OECD. ${ }^{7}$ Data for the current account are expressed as a fraction of GDP, while the short-term nominal interest rate is measured in percent (annualized).

Our results below are ordered according to the degree of openness of the four countries,

\footnotetext{
${ }^{5}$ Blanchard and Perotti also allow for a contemporaneous effect of taxes on spending. However, the effect is quantitatively negligible and it has become common to assume that government spending is predetermined vis-à-vis taxes, see Monacelli and Perotti [2006].

${ }^{6}$ Otherwise purely nominal changes in government spending due, for instance, increased public sector wages would not considered a change in spending, see Perotti [2005] for a detailed discussion.

${ }^{7}$ For the UK, we correct the time-series for private non-residential investment in 2005Q2. For this quarter the original numbers are distorted, because accounting rules make the transfer of nuclear reactors across different corporations appear as a large blip in private investment. We replace the observation for 2005Q2 combining the value for $2005 \mathrm{Q} 1$ and the growth rate for $2005 \mathrm{Q} 2$ implied by the values reported in table 1 of National Statistics [2006] for business investment excluding the exceptional transfer.
} 
measured by the share of imports (imports of goods and services, value, national accounts basis) in GDP. In our sample period imports account for 12, 18, 27 and 29 percent of GDP on average for the US, Australia, the UK, and Canada, respectively.

\subsection{Results}

We compute the effects of a government spending shock on the basis of the estimated VAR model. Figure 1 shows the results, displaying, in each panel, the impulse responses to an exogenous increase in government spending by one percent of trend output. The columns show the responses for the four countries, while the rows show the dynamic adjustment of output and its components. All variables are measured in units of trend output. In each case, the solid line represents the point estimate, while the shaded areas indicate 90 percent confidence bounds obtained by bootstrap sampling.

The first row shows the endogenous response of government spending to the shock. It displays moderate persistence in all countries, although the spending increase is particularly short-lived in Australia. The response of output, shown in the second row, is also fairly moderate. On impact, we detect a sizeable increase in the US only. Our finding of moderate multipliers confirms earlier findings by Perotti [2005] for the post-1980 period. ${ }^{8}$ For the countries in our sample we also note that the impact effect on GDP decreases as trade openness increases, a finding in line with Beetsma et al. [2008] who study a sample of annual data for European countries.

Turning to the response of investment, displayed in the third row, we find that a fiscal expansion induces a substantial and protracted decline, with the exception of Australia where investment recovers quickly. In fact, in this case it starts to rise beyond its trend level after about one year. As noted by Corsetti and Müller [2006], we find the crowding-out of investment considerably larger in the US than in the more open countries of our sample.

The fourth row shows the response of the current account. While, initially, it increases somewhat in the US, its response is generally negative. This finding is in line with evidence reported by Corsetti and Müller [2006] and Monacelli and Perotti [2006]. ${ }^{9}$ The last row of Figure 1 shows the response of private consumption, which is fairly unresponsive. Traditionally,

\footnotetext{
${ }^{8}$ For the US this finding is also confirmed by studies relying on alternative identification schemes. Mountford and Uhlig [2009] also find small output effects on the basis of sign restrictions. Ramey [2010] identifies government spending shocks in US time series for the period 1969-2008. She computes spending shocks as the difference of actual spending growth and growth expected by professional forecasters. She finds a small output increase on impact only.

${ }^{9} \mathrm{Kim}$ and Roubini [2008], in contrast, find that the current account in the US tends to rise after fiscal expansions. Monacelli and Perotti [2006] provide a detailed discussion of possible explanations for the different findings.
} 
studies adopting the Blanchard-Perotti identification scheme, e.g. Blanchard and Perotti [2002], have reported a positive consumption response to government spending shocks, notably for the US. Yet, more recently, evidence based on this approach suggests a decline in the size of the multiplier on consumption (in the US), or even a negative response (for Germany, the UK and Canada), see Perotti [2005]. Evidence based on alternative identification schemes also suggests that consumption is fairly unresponsive to government spending shocks, see the survey in Hall [2009].

Table 1 provides a comprehensive summary of our results. It reports the cumulative responses to the shock at the end of the first, second, third and sixth year for all variables included in the VAR model. Standard errors obtained by bootstrap sampling are reported in parentheses. Quantities are measured in output units, while interest rates are measured in percentage points (annualized). In order to facilitate a comparison with our theoretical results below, we normalize the size of the government spending shock so that the cumulated response of government spending after four quarters is one percent of trend output.

In addition to the response of output and its components which we discussed above, we find that the response of taxes across countries is quite distinct. We observe a decline in revenues in the US and in Canada, but an increase in Australia. In the UK the response of taxes is somewhat muted. Interest rates, in turn, tend to fall in response government spending shocks, except for Australia, where after an initial decline, the cumulative effect is positive at the end of the second year. This behavior of interest rates has been noticed before, see, e.g, Perotti [2005] or Mountford and Uhlig [2009].

\section{An Open Economy Model with Habit Formation}

We consider a semi-small open economy that is populated by a large number of identical households and firms that have perfect foresight and live forever. The country is assumed to be semi-small in the sense that it is price-taker in international capital markets but is large enough on world good markets to influence the price of its export goods. ${ }^{10}$

\subsection{Households}

At each instant the representative household consumes domestic goods and foreign goods denoted by $c^{D}$ and $c^{F}$, respectively, which are aggregated by means of a CES function:

$$
c=\left[\varphi^{\frac{1}{\phi}}\left(c^{D}\right)^{\frac{\phi-1}{\phi}}+(1-\varphi)^{\frac{1}{\phi}}\left(c^{F}\right)^{\frac{\phi-1}{\phi}}\right]^{\frac{\phi}{\phi-1}},
$$

\footnotetext{
${ }^{10}$ More details on the model as well as the derivations of the results which are stated below are provided in an appendix which is available on request.
} 
where $\varphi$ is the weight of the domestic good in the overall consumption bundle $(0<\varphi<1)$ and $\phi$ corresponds to the intratemporal elasticity of substitution between domestic and foreign consumption goods.

The representative agent is endowed with a unit of time, supplies a fraction $n(t)$ as labor, and the remainder $l(t) \equiv 1-n(t)$ is consumed as leisure. At any instant of time, households derive utility not only from their current real consumption $c(t)$ but also from their current level of habits denoted by $s(t)$. Hence, assuming that the felicity function is additively separable in consumption and labor, the representative household maximizes the following objective function:

$$
U=\int_{0}^{\infty}\left\{\frac{1}{1-\epsilon}\left[\frac{c(t)}{(s(t))^{\gamma}}\right]^{1-\epsilon}-\gamma_{N} \frac{n(t)^{1+\frac{1}{\sigma_{N}}}}{1+\frac{1}{\sigma_{N}}}\right\} e^{-\beta t} \mathrm{~d} t
$$

where $\beta$ is the consumer's discount rate, $\epsilon>0$ corresponds to the coefficient of relative risk aversion, and $\gamma>0$ is the weight of habits $s$ in utility; $\sigma_{N}>0$ is the Frisch elasticity of labor supply (or intertemporal elasticity of substitution for labor supply).

The habitual standard of living is defined as a distributed lag over past real consumption:

$$
s(t)=\sigma \int_{-\infty}^{t} c\left(c^{D}(\tau), c^{F}(\tau)\right) e^{-\sigma(t-\tau)} \mathrm{d} \tau,
$$

where the parameter $\sigma$ indexes the relative weight of recent consumption in determining the reference stock $s$. Differentiating equation (4) w. r. t. time gives the law of motion of habit stock:

$$
\dot{s}(t)=\sigma[c(t)-s(t)]
$$

Intuitively, the larger $\sigma$, the greater the weight of consumption in the recent past in determining the stock of habits, and the faster the reference stock adjusts to current expenditure.

In line with Carroll, Overland and Weil [2000], we have assumed that the utility derived from current and past consumption takes an iso-elastic form. The felicity function for current and past consumption can be rewritten as $u(c, s)=\frac{1}{1-\epsilon}\left[(c)^{1-\gamma}\left(\frac{c}{s}\right)^{\gamma}\right]^{1-\epsilon}$ according to which agents derive utility from a geometric weighted average of absolute and relative consumption where $\gamma$ is the weight of relative consumption. If $\gamma=0$, the case of time separability in preferences obtains. Hence, the intertemporal marginal rate of substitution between consumption at date $t+1$ and consumption at date $t$ does not depend on consumption at other dates which implies a fixed rate of time preference along a constant consumption path outside the steady-state. As long as the consumption-based real interest rate is fixed, the temporal path for consumption is flat. Hence, following a negative income shock, agents with time separable preferences find optimal to leave unchanged their wealth by adjusting immediately consumption to its longrun level. In other words, the marginal propensity to consume out of real permanent income (henceforth MPC) is equal to one. If $\gamma$ is positive, agents care about their relative consumption 
in deriving utility. The intertemporal marginal rate of substitution now depends on the stock of habits. If habit-forming agents experience a negative income shock, they anticipate that their usual standard of living will be lower in the long-run which drives down the marginal utility of future consumption. Consequently, the intertemporal marginal rate of substitution rises which is reflected by an increase in the slope of the indifference curves along a constant consumption path. Since individuals' impatience increases, agents are induced to reallocate consumption towards the present. Put differently, faced with a negative income shock, habit-forming agents find it optimal to reduce their consumption only moderately in the short-run and thereby to disave to sustain their original standard of living. Henceforth, the short-run MPC is smaller than one.

Households supply $n(t)$ units of labor services for which they receive the wage rate $w(t)$. They hold the physical capital stock for which they receive the capital rental rate. In addition, they accumulate internationally traded bonds, $b(t)$, that yields net interest rate earnings $r^{\star} b(t)$, expressed in terms of the foreign good. Denoting by $Z$ lump-sum taxes, the flow budget constraint is equal to households' real disposable income less consumption $p_{c} c$ and investment $I$ expenditure:

$$
\dot{b}(t)=\frac{1}{p(t)}\left\{r^{\star} p(t) b(t)+\left(r^{K}(t)+\delta_{K}\right) k(t)+w(t) n(t)-p_{c}(p(t)) c(t)-I(t)-Z(t)\right\},
$$

where $p_{c}$ is the consumption price index and $p$ the relative price of the foreign good (or the terms of trade). Investment $I$ leads to capital accumulation:

$$
\dot{k}(t)=I(t)-\delta_{K} k(t)
$$

where $0 \leq \delta_{K}<1$ is a fixed depreciation rate.

\section{$3.2 \quad$ Firms}

A large number of identical and perfectly competitive firms produces a final good which can be consumed domestically, invested or exported. They use physical capital $k$ and labor $n$, according to a constant returns to scale production function, $Y=F(k, n)$, which is assumed to have the usual neoclassical properties of positive and diminishing marginal products. Factor markets are assumed to be competitive, so that capital and labor are paid their marginal products, i. e. , $F_{k}=r^{K}+\delta_{K}$ for capital and $F_{n}=w$ for labor. 


\subsection{Government}

The government finances public spending $g$ by raising lump-sum taxes $Z$ according to the following balanced condition $Z=g \cdot{ }^{11}$ Alternatively, we will also consider the case of distorsionary taxes. The rise in government spending is thus associated with a rise in the labor tax rate $\tau^{F}$ (labor tax paid by employers), which is adjusted accordingly to balance the government budget $g=\tau^{F} w n$.

\subsection{Macroeconomic Dynamics}

In an open economy model with a representative agent having perfect foresight, a constant rate of time preference and perfect access to world capital markets, we require that $\beta=r^{\star}$ in order to generate an interior solution. This standard assumption made in the literature implies that the marginal utility of wealth, $\lambda$, will undergo a discrete jump when individuals receive new information and must remain constant over time from thereon.

The adjustment of the semi-small open economy towards the steady-state is described by a fourth order dynamic system which comprises the accumulation equation of habits (i. e. , eq. (5)) and the dynamic equation for the terms of trade:

$$
r^{K}=r^{\star}+\dot{p} / p
$$

which equalizes the rates of return on domestic capital and foreign bonds. ${ }^{12}$ This equation governs the trade-off between investment in domestic capital and traded foreign bonds. ${ }^{13}$

The dynamics of consumption are determined by the difference between the consumptionbased real interest rate, $r^{c}=r^{\star}+\left(1-\alpha_{c}\right) \frac{\dot{p}}{p}$, and the rate of time preference, denoted by $\rho(t)$ :

$$
\frac{\dot{c}}{c}=\frac{1}{\epsilon}\left[1+\sigma \xi c^{\epsilon} s^{\gamma(1-\epsilon)}\right]\left[r^{\star}+\left(1-\alpha_{c}\right) \frac{\dot{p}}{p}-\rho(t)\right],
$$

where $0<\frac{1}{\epsilon}\left[1+\sigma \xi c^{\epsilon} s^{\gamma(1-\epsilon)}\right]<1 / \epsilon$ stands for the short-run intertemporal elasticity of substitution (henceforth, IES) under time non separable preferences. ${ }^{14}$ The optimal path for

\footnotetext{
${ }^{11}$ We assume that the government balances its budget instantaneously through lump-sum taxes. As Ricardian equivalence obtains in the present setup, results are unaffected by allowing for government debt as long as the path of government spending is unchanged.

${ }^{12}$ Since the number of predetermined variables $(s$ and $k$ ) equals the number of negative eigenvalues, and the number of jump variables ( $c$ and $p$ ) equals the number of positive eigenvalues, there is a unique two-dimensional convergent path towards the steady-state.

${ }^{13}$ In a two-good small open economy model, the terms of trade are exogenous. Investment dynamics are driven only by changes in labor supply which alter the return on capital, because the interest rate is unaffected by domestic developments. In contrast, if the economy is large enough to influence its terms of trade, domestic shocks affect investment dynamics also via changes in the return on foreign bonds.

${ }^{14}$ The shadow value of the reference stock, denoted by $\xi$, is equal to the present discounted value of marginal
} 
consumption displays two key features. First, the slope of the consumption path determined by the short-run IES is smaller than the usual IES equal to the inverse of the relative risk aversion (i.e. $1 / \epsilon)$. Hence, consumption reacts less to a change in $r^{c}$, and in particular to a rise in trade openness as reflected by a fall in the domestic content of consumption expenditure $\left(1-\alpha_{c}\right)$. Second, the rate of time preference is variable over time. The reason is that habits gradually adjust to their steady-state value which in turn leads to a discrepancy between the current and future marginal utility of consumption.

Denoting by $X$ the exports to the rest of the world, we impose a domestic good market clearing condition to fully describe the macroeconomic equilibrium: ${ }^{15}$

$$
\dot{k}=F(k, n)-c^{D}-X(p)-\delta_{k} k-g .
$$

where $c^{D}=\left(1-\alpha_{c}\right) p_{c} c$ denotes consumption of the domestic good.

Substituting (10) into (6) yields the current account equation which is equal to net interest earnings from traded bonds holding plus net exports:

$$
\dot{b}(t)=r^{\star} b(t)+\frac{X(p(t))}{p(t)}-c^{F}(t)
$$

with $c^{F}(t)=\alpha_{c} p_{c}(p(t)) c(t) / p(t)$ where $\alpha_{c}$ measures the import content of consumption expenditures.

\subsection{Steady-State}

We now briefly characterize the steady-state. The assumptions of constant returns to scale and an exogenously given world interest rate imply that the steady-state capital-labor ratio remains unchanged after a fiscal expansion. Since the steady-state value of the capital-labor ratio remains fixed, i. e. $\frac{\tilde{k}}{\tilde{n}}=\left(\frac{\alpha_{K}}{r^{\star}+\delta_{K}}\right)^{\frac{1}{1-\alpha_{K}}}$, the marginal product of labor and thereby the wage rate are also unaffected in the long-run. By substituting the wage rate into the labor supply decision evaluated at the steady-state, we get $\tilde{n}=\left[\frac{1}{\gamma_{N}} \overline{\tilde{p}}\left(1-\alpha_{K}\right)\left(\frac{\tilde{k}}{\tilde{n}}\right)^{\alpha_{K}}\right]^{\sigma_{N}}$. Hence, a decrease in private wealth measured in terms of the domestic good (i. e., a rise in $\bar{\lambda} / \tilde{p}$ ) stimulates labor supply in the long-run. Higher employment raises the marginal product of $k$ and thereby the capital stock so that $\tilde{k} / \tilde{n}$ is unchanged.

Setting $\dot{c}=\dot{p}=0$ and using the fact that real consumption coincides with the habit stock once the economy reaches the long-term equilibrium enables us to derive the steady-state level disutility of consumption experience, $u_{s} \leq 0$, which depreciates at the rate $\sigma$ :

$$
\xi(t)=-\int_{t}^{\infty} \gamma c^{1-\epsilon} s^{-[\gamma(1-\epsilon)+1]} e^{-(\delta+\sigma)(\tau-t)} \mathrm{d} \tau .
$$

Since an increase in $s$ reduces instantaneous welfare for a given level of real consumption, $\xi$ is negative.

${ }^{15}$ Exports are positively correlated with the relative price of foreign goods, i. e. $X_{p}>0$. An increase in $p$, makes the domestic good cheaper and thereby stimulates exports. 
of real consumption:

$$
\tilde{c}=\left[\left(\frac{\beta+\sigma}{\beta+\sigma(1-\gamma)}\right) \frac{p_{c} \bar{\lambda}}{\tilde{p}}\right]^{-\nu}
$$

where $\nu$ is the long-run IES. Denoting by a hat the rate of change relative to initial steady-state, eq. (12) can be rewritten as $\hat{c}=-\nu \hat{\bar{\lambda}}+\nu\left(1-\alpha_{c}\right) \hat{\tilde{p}}$. This equation shows that consumption is more sensitive to a change in the terms of trade $\hat{p}$ than in the case of time separable preferences and reacts more strongly to it, the less open an economy, i.e. the larger $\left(1-\alpha_{c}\right)$. The reason is a larger long-run IES, $\nu>1 / \epsilon{ }^{16}$ Moreover, consumption reacts more to a change in the shadow value of wealth $\hat{\bar{\lambda}}>0$. Hence, following a fall in the real permanent income, $\bar{\lambda}$ must increase less to produce a decline in real consumption. The smaller increase in the shadow of wealth in the case of habits also induces agents to supply less labor. As it shall become clear later, this mechanism plays a major role in driving the response of investment.

The market-clearing condition for the home good determines the steady-state value of the terms of trade. The relative price $\tilde{p}$ adjusts for the goods market to clear:

$$
Y(\bar{\lambda}, \tilde{p})=c^{D}(\bar{\lambda}, \tilde{p})+X(\tilde{p})+\delta_{K} k(\bar{\lambda}, \tilde{p})+g
$$

where we have rewritten $\tilde{c}^{D}=p_{c}\left(1-\alpha_{c}\right) \tilde{c}$ as $c^{D}(\bar{\lambda}, \tilde{p}) \cdot{ }^{17}$ Following a temporary fiscal expansion, government spending reverts back to its initial level. Since output is higher and consumption is lower, the terms of trade must deteriorate in the long-run.

Finally, we note that a linearized version of the intertemporal solvency condition relates the steady-state level of net foreign asset position to the long-run level of physical capital and to the stock of habits:

$$
\left(\tilde{b}-b_{0}\right)=\Phi_{1}\left(\tilde{k}-k_{0}\right)+\Phi_{2}\left(\tilde{s}-s_{0}\right)
$$

with $\Phi_{1}<0$ and $\Phi_{2}>0$ for all parametrization. ${ }^{18}$ A steady-state decrease in habits (increase in capital) causes a decumulation of the stock of foreign assets by inducing a drop in savings (a rise in investment). An additional feature of the eq. (14) is the dependency of the steady-state on initial conditions which implies that temporary shocks have long-run effects.

\footnotetext{
${ }^{16} \mathrm{By}$ noting that habits coincide with real consumption in the long run, setting $c=s$ into the iso-elastic function above yields a long-run IES denoted by $\nu$ equal to $\frac{1}{[\gamma+\epsilon(1-\gamma)]}$ which is higher than the standard IES $1 / \epsilon$ as long as $\epsilon>1$. By contrast, the reference stock is fixed over a short interval of time. Hence, the short-horizon and long-horizon elasticities do not coincide as long as $\gamma>0$.

${ }^{17}$ Equation (13) can be solved for the terms of trade as a function of $\bar{\lambda}$ and $g$, i. e. , $\tilde{p}=p(\bar{\lambda}, g)$, with $p_{\bar{\lambda}}>0$ and $p_{g}<0$. Substituting $p(\bar{\lambda}, g)$ into (12) enables us to express the steady-state consumption and physical capital as functions of the shadow value of wealth and government spending, i.e. $\tilde{c}=c(\bar{\lambda}, g)$, with $c_{\bar{\lambda}}<0$ and $c_{g}<0$, and $\tilde{k}=k(\bar{\lambda}, g)$, with $k_{\bar{\lambda}}>0$ and $k_{g}>0$.

${ }^{18}$ Remembering that $\tilde{c}=\tilde{s}$ and substituting $\tilde{c}=c(\bar{\lambda}, g)$ and $\tilde{k}=k(\bar{\lambda}, g)$ into (14) yields $\tilde{b}=b(\bar{\lambda}, g)$ with $b_{\bar{\lambda}}<0$ and $b_{g}>0$.
} 


\section{The Role of Habits in the Transmission of Government Spending: An Analytical Exploration}

In this section, we explore analytically the macroeconomic effects of a temporary fiscal expansion, emphasizing how habits modify the propagation mechanism. We suppose that at time $t=0$, the government raises public spending on the domestic good and removes the expansionary policy at time $T .{ }^{19}$ The higher $T$, the stronger is the persistence of the shock.

To analyze the adjustment of consumption and the current account it is convenient to abstract from capital accumulation. In this case the response of consumption is given by:

$$
\frac{\mathrm{d} c(0)}{\mathrm{d} g}=-\frac{\mu_{1}}{\sigma}\left[\frac{\mathrm{d} \tilde{c}}{\mathrm{~d} g}+c_{g}\left(1-e^{-\mu_{2} T}\right)\right]<0,
$$

where $\mu_{1}<0<r^{\star}<\mu_{2}$ are the stable and unstable root, respectively; the second term in brackets on the RHS of eq. (15) reflects the direct effect of government spending on consumption through the change in the relative price (for given shadow value of wealth); the first term in brackets captures the long-run change of consumption induced by the change in the shadow value of wealth (for given value of the terms of trade); it is given by: ${ }^{20}$

$$
\frac{\mathrm{d} \tilde{c}}{\mathrm{~d} g}=c_{\bar{\lambda}} \lambda_{g}\left(1-e^{-r^{\star} T}\right)+r^{\star} c_{g} \tilde{\chi}\left(e^{-r^{\star} T}-e^{-\mu_{2} T}\right)<0 .
$$

Since taxes must be raised to balance the budget, the consecutive fall in the real disposable income induces agents to permanently lower their real expenditure, as captured by $c_{\bar{\lambda}} \lambda_{g}<0 .{ }^{21}$

To have a better grasp of the initial reaction of consumption, let's further simplify the analysis and consider the case of a small open economy model where the relative price of foreign goods $p$ is exogenous. In this case we have $c_{g}=0$ so that the short-run change in consumption simplifies to $-\frac{\mu_{1}}{\sigma} \frac{\mathrm{d} \tilde{c}}{\mathrm{~d} g}$. If preferences are time separable (i. e. , $\gamma=0$ ), the stable root $\mu_{1}$ reduces to $-\sigma$ which results in a drop of real consumption by the same amount than in the long-run. Hence, $c$ adjusts instantaneously to its long-run equilibrium. If, in contrast, preferences are characterized by habits (i. e., $\gamma>0$ ), we have $\sigma>-\mu_{1}$, which implies that consumption reacts weakly to the drop in income. The initial decline of consumption is given by:

$$
\frac{\mathrm{d} c(0) / \tilde{c}}{\mathrm{~d} g / \tilde{Y}}=\frac{\mu_{1}}{\sigma} \frac{\nu}{\sigma_{N}-\omega_{c} \nu \frac{\mu_{1}}{\sigma} \frac{\sigma+r^{\star}}{r^{\star}-\mu_{1}}}\left(1-e^{-r^{\star} T}\right)<0,
$$

\footnotetext{
${ }^{19}$ We assume further that all agents perfectly understand at the outset the temporary nature of the policy change. Hence, at time $T$, there is no new information and thereby no jump in the marginal utility of wealth at this date.

${ }^{20}$ The multiplicative term $\tilde{\chi}>0$ in front of the second term on the RHS of eq. (16) is related to the underlying parameters shown in the appendix.

${ }^{21}$ Additionally, as reflected by $c_{g}<0$, the long-run terms of trade deterioration reduces consumption more by lowering the value of foreign bonds measured in domestic units which raises further the marginal utility of wealth.
} 
where $-\frac{\mu_{1}}{\sigma} \frac{\sigma+r^{\star}}{r^{\star}-\mu_{1}}>0$. Regardless of the type of preferences, agents smooth their real consumption as long as the shock is temporary. This smoothing behavior results in a smaller reaction of consumption than that after a permanent fiscal shock as reflected by the scaling term $0<\left(1-e^{-r^{\star} T}\right)<1$. Yet habit persistence further moderates the initial drop of $c$. To see it more clearly, assume that labor supply is inelastic, i.e. $\sigma_{N}=0$; in this case, the above expression simplifies to $\frac{r^{\star}-\mu_{1}}{\sigma+r^{\star}}\left(1-e^{-r^{\star} T}\right)$. As $\gamma$ gets closer to unity, the speed of adjustment $\left|\mu_{1}\right|$ gets smaller which results in a weaker reaction of $c$ on impact. This consumption behavior is due to the time preference rate which is variable over time. Following a fiscal expansion, agents expect a long-term fall in their standard of living. However, when the fiscal expansion is implemented, the stock of habits does not change, so that the marginal utility of current consumption exceeds that of future consumption. This provides a strong incentive to reallocate expenditure to the present and implies a MPC below unity in the short-run.

Turning to the case of a semi-small open economy, note that the increase in government spending on domestic goods appreciates the terms of trade. This exerts a negative impact on consumption, because domestic consumption consists to a large extent of domestically produced goods whose relative price is temporarily increased. Hence, consumption drops by a larger amount relative to the small open economy case. Habits also determine the strength of this channel. This can be seen more formally by linearizing the first-order condition for consumption; evaluating at time $t=0$ and totally differentiating gives:

$$
\frac{\mathrm{d} c(0)}{\tilde{c}}=\frac{\beta+\sigma(1-\gamma)}{\epsilon[\beta+\sigma(1-\gamma)]+\sigma \gamma}\left[\left(1-\alpha_{c}\right) \frac{\mathrm{d} p(0)}{\tilde{p}}-\frac{\mathrm{d} \bar{\lambda}}{\bar{\lambda}}\right]
$$

where the term $\frac{\beta+\sigma(1-\gamma)}{\epsilon[\beta+\sigma(1-\gamma)]+\sigma \gamma}$ is a decreasing function of $\gamma$. Hence, as $\gamma$ gets closer to unity, real consumption falls by a smaller amount for a given initial terms of trade improvement $\frac{\mathrm{d} p(0)}{\tilde{p}}<0$. Additionally, an increase in trade openness (i.e. a decrease in $\left.\left(1-\alpha_{c}\right)\right)$ moderates the initial drop of consumption following a fall in $p$ by isolating consumption from the change in the terms of trade. In a polar case where the import content $\alpha_{c}$ is equal to 1 , real consumption does no longer depend on the relative price and the analysis for a small open economy model applies.

We now turn to the adjustment of the current account while still abstracting from capital formation in order to highlight the role of habits. The initial response of the current account is given by:

$$
\frac{\tilde{p} \mathrm{~d} c a(0)}{\tilde{Y}}=-e^{-r^{\star} T} \frac{\mathrm{d} g}{Y}+\omega_{c}\left(\frac{\sigma+\mu_{1}}{r^{\star}-\mu_{1}}\right) \frac{\mathrm{d} c(0)}{\tilde{c}}
$$

where $\mathrm{d} c(0) / \tilde{c}<0$ is given by expression (17). The first term on the RHS of (19) represents the negative impact of consumption smoothing behavior on the current account, regardless of the specification of preferences. In the case of time separable preferences, $\mu_{1}=-\sigma$ so that the second term on the RHS of (19) vanishes. However, as $\gamma$ gets closer to unity, habit persistence 
gets stronger. This results in a smaller drop in consumption and thereby a greater current account deficit.

In a semi-small open economy model, exports are price-elastic and thereby fall by a smaller amount than that in a small open economy framework. In addition, as discussed previously, due to a higher consumption-based real interest rate, consumption declines by a larger amount in the short-run. Linearizing (11), evaluating at time $t=0$, and differentiating yields the initial reaction of the current account:

$$
\frac{\tilde{p} \mathrm{~d} c a(0)}{\tilde{Y}}=\left[\omega_{X}\left(\nu_{X}-1\right)+\phi\left(1-\alpha_{c}\right) \omega_{c} \alpha_{c}\right] \frac{\mathrm{d} p(0)}{\tilde{p}}-\alpha_{c} \omega_{c} \frac{\mathrm{d} c(0)}{\tilde{c}} \lessgtr 0,
$$

where $\nu_{X}$ stands for the price-elasticity of exports, $\phi$ the intratemporal elasticity of substitution between foreign and domestic goods, $\left(1-\alpha_{c}\right)$ the domestic content of consumption expenditure. The response of the current account to changes of the terms of trade depends on the relative importance of valuation and substitution effects. For all parametrizations which we consider below, the latter effect dominates such that an appreciation of the terms of trade $(\mathrm{d} p(0)<0)$ reduces the current account, i.e. the Marshall-Lerner condition is satisfied. The second term on the RHS of (20) reflects the effect of consumption changes on imports: the current account may improve as a result of reduced consumption. Consumption inertia greatly moderates the drop in $c^{F}$ and thereby makes a current account deficit more likely. ${ }^{22}$

In order to build up intuition regarding the dynamics of investment, and to clarify the role of habits in driving its response to a fiscal shock, we turn to the first-order condition given by eq. (8). It equates the rate of return on domestic capital and on traded bonds. Following an increase in government spending, households supply more labor which raises the marginal product of capital and thereby $r^{K}=F_{k}-\delta_{K}$. At the same time, government spending appreciates the terms of trade, which overshoot initially so as to depreciate along the transitional path. This raises the return on bonds for a given world interest rate (i.e. $r^{\star}+\dot{p} / p$ ). Depending on whether $r^{K}$ exceeds $r^{\star}+\dot{p} / p$ or not, agents are induced to accumulate or decumulate physical capital.

Both the shock's duration and the specification of preferences matter for the response of $r^{K}$ via labor supply decisions. Consider first the case of time separable preferences. If the shock is long-lived, the increase in the marginal utility of wealth and thereby the rise in labor supply is large enough to push up $r^{K}$ above $r^{\star}+\dot{p} / p$ so that investment is crowded-in. Conversely, after a short-lived shock, the rise in labor supply is smaller as the marginal utility of wealth increases less. Because the rise in $r^{K}$ is not large enough, investment is crowded-out, see the analysis of Baxter and King [1993] within a closed-economy context.

\footnotetext{
${ }^{22}$ Whereas the current account enters unambiguously in a deficit in a small open economy model, such a result does no longer hold in a semi-small open economy model as the higher consumption based real interest rate counteracts the smoothing effect, and more so as the shock is shorter-lived.
} 
Yet if, as a result of habits, agents care about past consumption, investment is generally crowded-out by government spending irrespectively of the length of the shock. In this case, labor supply increases less as a result of a smaller increase in the marginal utility of wealth. The rate of return on foreign bonds therefore tends to exceed the return on domestic capital which, in turn, induces agents to decumulate domestic capital.

\section{Temporary Fiscal Expansion: A Quantitative Exploration}

In this section, we analyze the effects of a temporary rise in government spending quantitatively. For this purpose we solve the model numerically. In the following we thus first discuss parameter values before turning to the long-term and short-term effects of the fiscal shock.

\subsection{Baseline Parametrization}

We start by describing the calibration that we use as a baseline. The world interest rate which is equal to the subjective time discount rate $\beta$ is set to $3.5 \%$. One period of time corresponds to a year. The elasticity of substitution between domestic and foreign goods $\phi$ is set to 1.5. Exports are assumed to take a power form $X=X(p)=\gamma_{X} p^{\nu X}$ with $\gamma_{X}>0$. The terms of trade elasticity of exports denoted by $\nu_{X}$ is set to 0.8 in line with estimates by Bayoumi [1999]. Government spending as a share of GDP $g / Y$ is $20 \%$. Finally, the production function takes a Cobb-Douglas form $Y=F(k, n)=k^{\alpha_{K}} n^{1-\alpha_{K}}$ with the share of capital in output assumed to be equal to 0.4 . Finally, we set $\delta_{K}$ to 0.035 so as to be consistent with a ratio investment-GDP equal to $20 \%{ }^{23}$ All the previous parameter values remain unchanged in the analysis below. Next, we turn to the parameters for which we conduct some sensitivity analysis.

Our baseline setting for the weight of the domestic $\operatorname{good} \varphi$ is 0.90 so as to be consistent with an import content of consumption $\left(\alpha_{c}\right)$ of $20 \%$. This allows us to target an import share of 12 percent, in line with the average value for the US during the period 1980-2007. Two additional critical parameters are the weight of habits in utility, $\gamma$, and the speed $\sigma$ at which the standard of living catches up with current consumption. Empirical results by Sommer [2007] suggest a value for $\gamma$ between $0.7-0.8$. We set $\gamma$ to 0.8 . The relative-risk aversion parameter, $\epsilon$, is set to 1.5. We set $\sigma$ to 0.6 which means that the time required to close $95 \%$ of the discrepancy between $s(t)$ and $c(t)$ following a change in $c(t)$ is roughly five periods. The last critical parameter is the intertemporal elasticity of substitution for labor supply $\sigma_{N}$. In our baseline parametrization, we set $\sigma_{N}=0.4$, in line with evidence reported by Domeij and Flodén [2006].

\footnotetext{
${ }^{23}$ For the baseline parametrization, private consumption expenditure and exports expressed as a share of GDP are $62 \%, 12 \%$ respectively. The trade balance is balanced in the initial steady-state.
} 
We consider a rise in government spending by 1 percentage point of initial output. Regarding the duration of the fiscal shock, we consider three different scenarios: a short-lived $(T=4)$, a medium-lived $(T=10)$, and a long-lived $(T=25)$ fiscal shock. As a baseline scenario, we consider a short-lived fiscal shock. In this case the cumulative increase in government spending corresponds approximately to the cumulative increase in US government spending six years after an exogenous spending shock according to the estimates reported in Table 1 above. For $T=4$, we also conduct a sensitivity analysis with respect to the elasticity of labor supply (i.e. we set $\sigma_{N}$ to 0.2 and 1 ) and the degree of openness (i.e. we set $\varphi=0.6$ to target an importto-GDP ratio of $28 \%$ ). In addition, we consider the possibility that government spending is financed by distortionary labor taxes.

\subsection{Long-Run Effects of Temporary Fiscal Expansion}

A temporary increase in government spending has permanent or long-run effects, because the model features the zero-root property. ${ }^{24}$ Since government spending reverts back to its initial level at time $T$, changes in the long-run, i.e. in the steady-state, are only driven by the change in the equilibrium value of the marginal utility of wealth. Confronted with a fall in their disposable income, agents are induced to permanently lower real consumption and increase labor supply. This stimulates capital accumulation by raising the marginal product of capital. As both factors of production increase in the long-run, output also increases. Longrun consumption, instead, falls such that the terms of trade deteriorate in the long-run for the goods market to clear.

In panel A of Table 2 we report numerical results. Quantitatively the long-run effects are small. Consumption, for instance, falls by 0.03 percent of initial output in the long-run in response to short-lived fiscal shock. The effects tend to increase in the duration of the shock, but are generally moderate. Moreover, it turns out that the role of habits for the long-run effects is quite limited. Intuitively, while steady-state consumption is more sensitive to the wealth effect in the case of habits, it also reacts more to the terms of trade deterioration that lowers the marginal utility of wealth when measured in terms of the domestic good (see eq. $(12))$.

\subsection{Short-Run effects}

We now turn to the short-run effects of the fiscal expansion. We still consider the short-lived spending shock as our baseline scenario, but we also refer to a long-lived shock to build up

\footnotetext{
${ }^{24}$ Technically, this follows from the assumption $\beta=r^{\star}$, which requires the joint determination of the transition and the steady-state.
} 
intuition. Panels $\mathrm{B}$ and $\mathrm{C}$ of Table 2 report results for this case, as well as for a number of alternative scenarios. While panel $\mathrm{B}$ reports the impact response, panel $\mathrm{C}$ reports the cumulative responses over the first three years after the shock.

The transitional paths of key variables under the baseline scenario are displayed in Figure 2. The responses of consumption, GDP, investment and current account are expressed in percent of initial steady-state output, employment and the terms of trade are expressed in percentage deviations from the initial steady state. Horizontal axes measure years.

Before analyzing in the detail the role of habits in shaping the short-run dynamics in response to a temporary increase in government spending, we recall our first set of empirical observations established in section 2. We found that in all countries of our sample, an exogenous increase in government spending does not affect consumption very much, raises output, and induces a simultaneous decline of investment and the current account.

In the following, we discuss the predictions of our model for the behavior of these variables under time-separable preferences and in the presence of habit formation. In a nutshell, while government spending lowers consumption, raises labor supply, and improves the terms of trade in both cases, the response of labor supply and consumption is more moderate in the presence of habits. As a consequence, the model will generally predict a simultaneously decline of investment and the current account only in this case.

$<$ Please insert Table 2 about here $>$

Figure 2(a) displays the dynamic adjustment of consumption in the baseline case with habits (solid line) and compares it to alternative scenarios. The dashed-dotted line shows results for time-separable preferences, while the dotted (dashed) line shows results for a high labor supply elasticity (high degree of openness).

The transitional path of consumption is quite distinct, depending on whether agents care about past consumption or not. If $\gamma=0$, the rate of time preference is fixed so that consumption monotonically increases towards its new steady-state, driven by a higher consumption-based real interest rate. Instead, if $\gamma=0.8$, the initial rise in the rate of time preference $\rho$ is large enough to offset the increase in the consumption-based real interest rate and leads to a decreasing temporal path for households' real expenditure. The gradual decline in the reference stock reduces $\rho$ which falls monotonically. Finally, after 6 years, the declining time preference rate equalizes the consumption-based real interest rate's hump-shaped transitional path, which induces a rising temporal path for consumption afterwards. 
Relative to VAR evidence, we note that the model predicts a decline of consumption under all specifications. However, as shown in the first row of panel B of Table 2, the crowding-out of consumption shrinks from $-0.20 \%$ to $-0.10 \%$ if we move from the time-separable preferences to the habits specification of preferences.

In line with our theoretical discussion in section 4, the sign of the investment response depends on the shock's persistence as well as on the preferences specification. The cumulative responses reported in the fourth line of panel $\mathrm{C}$ of Table 2 show that a fiscal expansion crowds-in investment by about $0.15 \%$ of initial GDP on impact after a long-lived shock while investment is crowded-out by $2.1 \%$ if the shock is short-lived and preferences are time-separable. In contrast, regardless of the shock's persistence, investment is always crowded-out in a model with habits, as agents are induced to supply less labor than in the case of time separable preferences due to a lower rise in the shadow value of wealth. As a result, the return on domestic capital remains low relative to the return on traded bonds.

For our baseline scenario, we find that the cumulative response of investment is $-0.72 \%$ of GDP on impact and $-2.29 \%$ after three years, see the fourth line of panels B and C of Table 2 , respectively. These predictions are close to the evidence for the US obtained from the VAR model (see Table 1).

Finally, Figure 2(e) displays the dynamics of investment for the short-lived shock while allowing for different preference specifications. In this case, investment always falls, but more so in case of habits or if labor supply is weakly responsive (i e., $\sigma_{N}=0.2$ ).

$<$ Please insert Figures 1(a), 1(b), 1(c), 1(d), 1(e), 1(f) about here >

The reaction of the current account is reported in the sixth line of panel B of Table 2. We find that the neoclassical model is unable to account for a simultaneous decline of investment and the current account in the case of time separable preferences. In particular, following a short-lived fiscal expansion, investment is crowded-out and the current account enters in surplus in the short-run (see Figure 2(f)). By contrast, in the presence of habits, an expansionary fiscal policy drives down investment and worsens the external asset position as savings decline more in this case.

The fifth line of panel $\mathrm{C}$ of Table 2 reports results which vary markedly across cases, from a current account deficit of $-0.2 \%$ of initial GDP (for $T=25$ and $\gamma=0.8$ ) to a surplus by $0.02 \%$ (for $T=4, \gamma=0$, and $\varphi=0.6$ ). Note, however, that while allowing for habits improves the predictions of the neoclassical model, it still fails to predict the size of the current account deficits reported in Table 1. 
We now discuss the GDP response. As shown in the seventh line of panel B of Table 2, in all scenarios, output increases, as labor supply rises. While the model underpredicts the size of the initial response of GDP found in the data (see Table 1), it predicts pretty well the slowdown in GDP growth and the negative response of GDP found for the US economy after one year and a half as displayed in Figure 1. The slowdown in GDP growth originates from the fall in the growth rate in hours worked, as portrayed in Figure 2(c). Households supply labor at a smaller rate as the terms of trade deterioration lowers the real wage. Additionally, the crowding-out of investment reduces further GDP growth which becomes negative after one year. Since the model with habits predicts a smaller increase in labor supply and a stronger decumulation of capital, the GDP response is smaller across all scenarios, as shown in the seventh line of panel B of Table 2. At the time the fiscal policy is removed, the economy experiences an investment boom, as portrayed in Figure 2(e). Finally, as stressed by Baxter and King [1993], the response of GDP to a fiscal shock displays a great sensitivity to labor supply responsiveness. Considering a short-lived shock, the cumulative response of GDP for a three-year horizon summarized in the last line of panel $\mathrm{C}$ of Table 2 varies from about zero with habits and a low $\sigma_{N}$ to $0.5 \%$ with time separable preferences and a high $\sigma_{N}$.

\subsection{The Role of Trade Openness}

We now take up the question to what extent the degree of openness alters the fiscal transmission mechanism within the neoclassical model. We do so against the background of our second set of observations established in section 2 above. We have documented that, for the four countries in our sample, an increase in government spending has a smaller effect on investment and GDP, while it induces a larger current account deficit in more open economies. In the following, we contrast the dynamic adjustment triggered by the fiscal shock in the baseline scenario with an import-to-GDP ratio of 12 percent with results for a more open economy with an import-toGDP ratio of 28 percent.

As illustrated by the dashed line in Figure 2(a), consumption falls less in more open economies. As stressed in section 4, a rise in trade integration moderates the drop in consumption, because real expenditures are less sensitive to changes in the terms of trade, once the weight of imported goods in the consumption basket is smaller (see eq. (18)).

Turning to investment and how its response changes with openness, we first note that, as shown in the sixth line of panel A of Table 2, more open economies experience a smaller terms of trade deterioration in the long-run. ${ }^{25}$ Hence, the rate of depreciation in the terms of trade

\footnotetext{
${ }^{25}$ In this case the terms of trade deteriorate less to clear the good market, because exports account for a larger fraction of GDP.
} 
is lower along the transitional path and the return on foreign bonds increases less. Ceteris paribus, this implies a smaller drop in investment in more open economies, as illustrated by the numerical results reported in panels $\mathrm{B}$ and $\mathrm{C}$ of Table 2. Hence, the model's predictions conform with the VAR evidence; yet, we also note that the role of openness for the investment response is limited from a quantitative point of view, in particular in the case $\gamma=0$.

Openness also matters for the response of the current account to fiscal shocks. Specifically, inspection of equation (20) reveals that the initial fall in $p$ exerts a larger negative impact on the current account, as the GDP shares of exports $\omega_{X}$ and imports $\omega_{c} \alpha_{c}$ rise as a result of a higher degree of openness. At the same time, a higher import content also implies that the fall in consumption leads to a stronger decline of imports. However, for our baseline scenario the first effect dominates, as shown by numerical results reported in panels B and C of Table 2 , the response of the current account is stronger in more open economies. Note that this implies a larger current account deficit in the case of habits, but a larger surplus in the case of time-separable preferences.

Finally, we investigate how openness alters the output response to the fiscal shock. On the one hand, as discussed above, investment is crowded-out less in more open economies. On the other hand, labor supply rises by a smaller amount in more open economies. ${ }^{26}$ Our numerical results suggest that the second effect dominates: output increases less in more open economies. Specifically, Figures 3(a) and 3(b) plot the cumulative response of GDP over a three-year horizon against different values for the exports-to-GDP ratio, for the case of time-separable preferences and the case of habits, respectively. The cumulative output response declines in openness under both preference specifications, although the effect is somewhat less pronounced in the case of habits, reflecting the stronger sensitivity of investment to trade openness.

$<$ Please insert Figures 2(a), 2(b) about here $>$

\section{Sensitivity Analysis}

In this subsection, we discuss further the implications of the duration of the shock and conduct a sensitivity analysis with respect to the financing scheme of government spending.

\footnotetext{
${ }^{26}$ This is because openness moderates the rise in the shadow value of wealth triggered by the fiscal shock. Intuitively, in more open economies, as imports account for a larger fraction of consumption, the government's claim on domestic resources is less damaging to the households' wealth.
} 


\subsection{Shock Duration}

The duration of the shock is an important determinant for the transmission of fiscal policy measures. In fact, assuming time separable preferences, we find that the sign of the responses of investment and current account depends on the length of the shock. In the presence of habits, the shock's duration affects the size of the effects. This is illustrated in Table 2 which reports results for $T=4, T=10$ and $T=25$.

We find that, as the shock's length decreases, the current account deteriorates less, while investment is crowded-out more. Intuitively, as the shock is less persistent, the rise in the return on physical capital is smaller so that agents are induced to accumulate foreign bonds relative to capital. Yet the current account will move into deficit, as households smooth consumption and lower their savings.

\subsection{Labor Tax-Financing Fiscal Shocks}

So far we assumed that taxes are lump-sum. Instead, we now consider the possibility that taxes are distortionary. Specifically, we assume that firms face a labor cost equal to $w^{F}=w\left(1+\tau^{F}\right)$, with $\tau^{F}$ denoting payroll taxes (i. e. , the employer's part of labor taxes). We let taxes adjust so as to balance the government budget in each period: $\tau^{F} w n=g$. Since the wage $w$ is equal to the marginal product of labor adjusted of labor tax, i.e. $\frac{F_{n}}{1+\tau^{F}}$, labor supply decisions are now based on $\tilde{n}=\left[\frac{\lambda}{p} \gamma_{N} \frac{\left(1-\alpha_{K}\right)}{\left(1+\tau^{F}\right)}\left(\frac{\tilde{k}}{\tilde{n}}\right)^{\alpha_{K}}\right]^{\sigma_{N}}$.

By assumption, an increase in government spending triggers a rise in labor income taxes. Moreover, since higher labor income taxes reduce the households' incentive to work, the consecutive fall in the tax base requires an additional increase in the tax rate. Results for the case of distortionary taxes are shown in Table 2, assuming $T=10$ and habit formation. As a consequence, GDP falls by about by $0.3 \%$ on impact in response to a spending shock in this case, see also Baxter and King [1993] for a closed economy analysis. Investment, consumption and the current account also fall more strongly. ${ }^{27}$

\section{Conclusion}

In this paper we have shown that the introduction of a habit index into the utility function helps improving the predictive power of the open economy version of the neoclassical model. In

\footnotetext{
${ }^{27}$ Clearly, while distortionary taxes are the empirically relevant case, the effect of distortionary taxes on the transmission of government spending shocks is likely to be overstated as a result of assuming that the government budget is balanced in each period. A detailed analysis of debt policies is beyond the scope of the present paper, however.
} 
particular, a robust observation emerging from our VAR analysis is that government spending tends to crowd-out both investment and the current account. Allowing for habit formation enables the model to account for this finding.

Following a temporary rise in government spending, consumption falls, labor increases and terms of trade improve on impact, whether agents care about their past consumption or not. Yet, in the case of habits, the increase in labor supply is more moderate. This, ceteris paribus, lowers the return on domestic capital relative to the return on foreign bonds and induces a decumulation of domestic capital relative to foreign bonds. In response to a temporary rise in government spending, overall savings decline, because households smooth consumption. However, only in the case of habits is the drop in savings large enough for both investment and the current account to decline.

A second observation which emerges from our VAR analysis is that the degree of openness appears to affect fiscal policy transmission systematically. We therefore analyze the effect of trade openness on fiscal policy transmission within the neoclassical model. In line with the evidence, we find that higher trade openness moderates substantially the crowding-out of investment and amplifies the current account deficit (in the case of habits). In addition, we find that the output effects of government spending decline in openness in line with the evidence. This result may also provide a rationale for an interesting finding by Perotti [2005]. He documents declining output effects of government spending when comparing time-series evidence for the pre-1980s with the post-1980s period; trade openness certainly increased considerably between the two sample periods.

In concluding we stress a number of caveats. First, our time series evidence on openness can only be considered tentative, as it is based on observations for four countries. Reassuringly, however, it confirms earlier findings for a larger sample by Beetsma et al. [2008]. Second, regarding the model's performance, we note that the model fails to match the evidence quantitatively along a number of dimensions. Notably, it fails to predict the size of current account deficits. Finally, while a number of studies provide evidence that government spending tends to depreciate exchange rates, at least for the US (see, e.g., Enders, Müller and Scholl [2010]), the neoclassical model predicts that government spending appreciates the terms of trade, at least in the short-run. We leave a further analysis of these issues for future research.

\section{References}

Backus, David K., Patrick J. Kehoe, and Finn E. Kydland (1994) Dynamics of the Trade Balance and the Terms of Trade: The J-Curve?. American Economic Review 84(1), 84-103.

Bayoumi, Tamim (1999) Estimating Trade Equations from Aggregate Bilateral Data. IMF Working Paper No. 74. 
Baxter, Marianne and Robert G. King (1993) Fiscal Policy in General Equilibrium. American Economic Review, 83(3), 315-334.

Beetsma, Roel, Massimo Giuliodori, and Franc Klaassen (2008) The Effects of Public Spending Shocks on Trade Balances and Budget Deficits in the European Union. Journal of the European Economic Association 6(2-3), 414-423.

Blanchard, Olivier J., and Roberto Perotti (2002) An Empirical Characterization of the Dynamic Effects of Changes in Government Spending and Taxes on Output. Quarterly Journal of Economcis 177, 1329-1368.

Buiter, Willem H. (1987) Fiscal Policy in Open, Interdependent Economies, in A. Razin and E. Sadka (eds.) Economic Policy in Theory and Practice, St. Martins Press, New York.

Burnside Craig, Martin Eichenbaum, and Jonas D. M. Fisher (2004) Fiscal Shocks and their Consequences. Journal of Economic Theory 115, 89-117.

Campbell, John Y., and John H. Cochrane (1995) By Force of Habit: A Consumption-Bases Explanation of Aggregate Stock Market Behavior. Journal Of Political Economy, 107(2), 205-251.

Carroll, Christopher D., Jody Overland, and David N. Weil (2000) Saving and Growth with Habit Formation. American Economic Review 90(3), 341-355.

Christiano, Lawrence J. and Martin Eichenbaum and Charles L. Evans (1999) Monetary Policy Shocks: What Have We Learned and to What End? in: John B. Taylor and Michael Woodford (eds.), Handbook of Macroeconomics, 319-347.

Corsetti, Giancarlo, and Gernot Müller (2006) Twin Deficits: Squaring Theory, Evidence and Common Sense. Economic Policy 48, 597-638.

Domeij, David, and Martin Flodén (2006) The Labor-Supply Elasticity and Borrowing Constraints: Why Estimates are Biased. Review of Economic Dynamics 9, 242-262.

Enders, Zeno, Gernot Müller and Almuth Scholl (2010) How do Fiscal and Technology Shocks affect Real Exchange Rates? New Evidence for the United States. Journal of International Economics, forthcoming.

Galí, Jordi, J. David López-Salido and J. Vallés (2007) Understanding the Effects of Government Spending on Consumption. Journal of the European Economic Association 5, 227-270.

Hall, Robert E. (2009) By How Much Does GDP Rise If the Government Buys More Output? Brookings Papers on Economic Activity Fall, 183-231.

Karayalcin, Cem (1999) Temporary and Permanent Government Spending in a Small Open Economy Model. Journal of Monetary Economics 43, 125-141.

Karayalcin, Cem (2003) Habit Formation and Government Spending in a Small Open Economy. Macroeconomic Dynamics 7, 407-423.

Kim, Soyoung and Nouriel Roubini (2008) Twin deficit or twin divergence? Fiscal policy, current account, and real exchange rate in the U.S. Journal of International Economics 74, 362-383.

Monacelli, Tommaso and Robert Perotti (2006) Fiscal Policy, the Trade Balance and the Real Exchange Rate: Implications for International Risk Sharing, mimeo.

Mountford, Andrew and Harald Uhlig (2009) What are the Effects of Fiscal Policy Shocks? Journal of Applied Econometrics 24, 960-992.

Müller, Gernot (2008) Understanding the Dynamic Effects of Government Spending on Foreign Trade. Journal of International Money and Finance 27(3), 345-371.

National Statistics (2006) First Release - Business investment, website: www.statistics.gov.uk

Perotti, Roberto (2005) Estimating the Effects of the Fiscal Policy in OECD Countries. CEPR Discussion Paper 4842.

Ramey, Valerie A. (2010) Identifying Government Spending Shocks: It's All in the Timing Quarterly Journal of Economics, forthcoming.

Sommer, Martin (2007) Habit Formation and Aggregate Consumption Dynamics. The B.E. Journal of Macroeconomics 7(1) (Advances), Article 21.

Turnovsky, Stephen J., and Partha Sen (1991) Fiscal Policy, Capital Accumulation, and Debt in an Open Economy. Oxford Economic Papers 43, 1-24. 

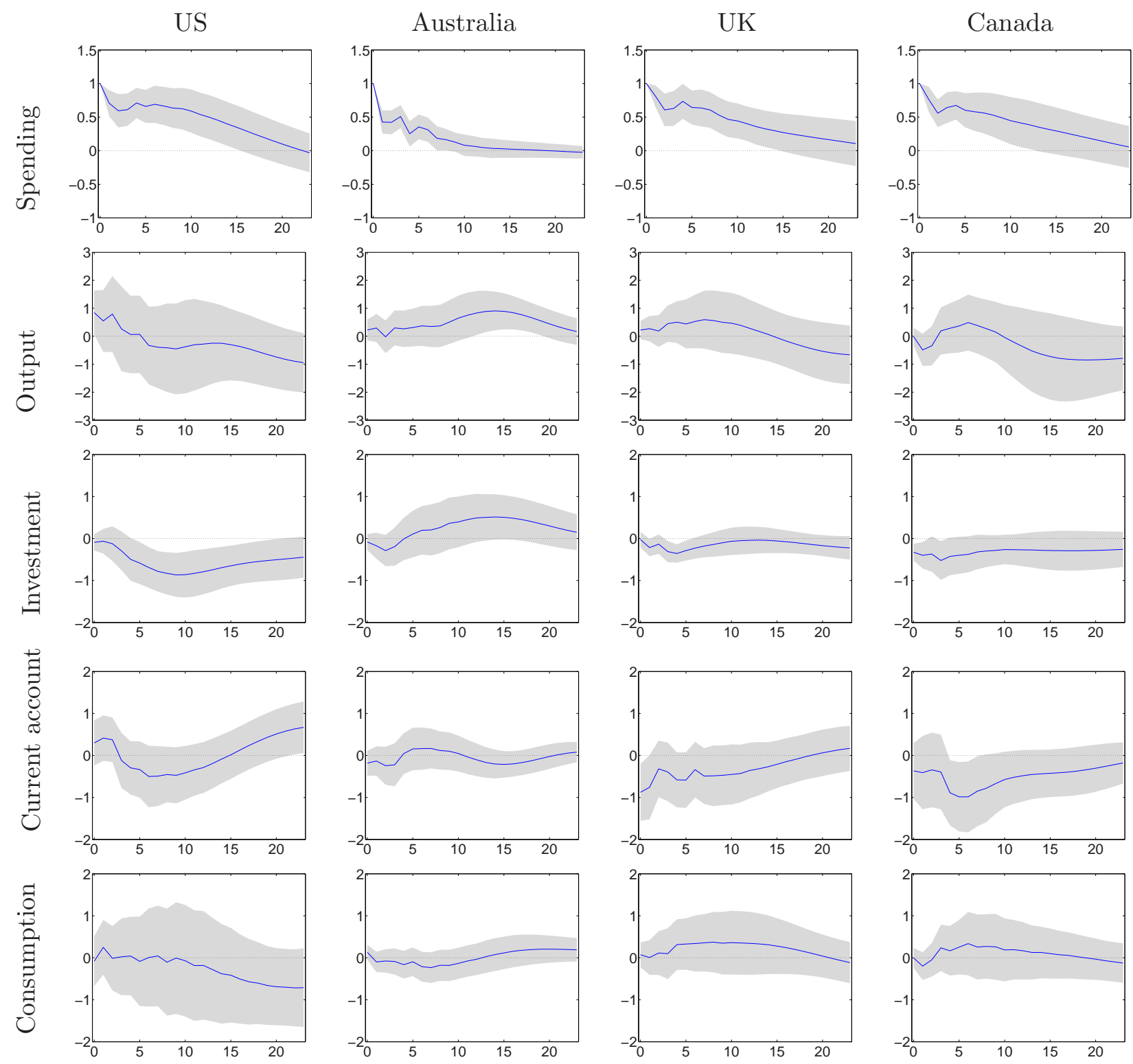

Figure 1: Effect of government spending shocks. Notes: variables are measure in percentage points of output. Results for baseline specification are displayed by solid lines with shaded area indicating 90 percent confidence bounds obtained by bootstrap sampling; sample 1980-2007, responses of taxes and interest rate not shown, response of consumption is obtained from VAR model where investment is replaced by consumption. 
Table 1: Cumulative Impulse Responses to Government Spending Shock

\begin{tabular}{|c|c|c|c|c|c|}
\hline & Horizon & US & Australia & UK & Canada \\
\hline Government & $1 \mathrm{yr}$ & $1.00(0.00)$ & $1.00(0.00)$ & $1.00(0.00)$ & $1.00(0.00)$ \\
\hline \multirow[t]{3}{*}{ Spending } & $2 \mathrm{yrs}$ & $1.94(0.16)$ & $1.47(0.18)$ & $1.86(0.16)$ & $1.82(0.18)$ \\
\hline & $3 \mathrm{yrs}$ & $2.76(0.40)$ & $1.65(0.31)$ & $2.46(0.33)$ & $2.45(0.46)$ \\
\hline & $6 \mathrm{yrs}$ & $3.69(1.11)$ & $1.71(0.52)$ & $3.34(0.93)$ & $3.34(1.14)$ \\
\hline \multirow[t]{4}{*}{ Net Taxes } & $1 \mathrm{yr}$ & $-0.97(0.74)$ & $0.07(0.49)$ & $0.21(0.49)$ & $-1.00(0.34)$ \\
\hline & $2 \mathrm{yrs}$ & $-2.41(1.64)$ & $0.90(0.99)$ & $0.14(1.10)$ & $-1.66(0.78)$ \\
\hline & $3 \mathrm{yrs}$ & $-3.75(2.42)$ & $2.06(1.48)$ & $0.26(1.90)$ & $-2.01(1.07)$ \\
\hline & $6 \mathrm{yrs}$ & $-4.93(3.64)$ & $4.89(2.09)$ & $-0.75(3.97)$ & $-3.38(1.92)$ \\
\hline \multirow[t]{4}{*}{ Output } & $1 \mathrm{yr}$ & $0.84(1.05)$ & $0.34(0.56)$ & $0.37(0.39)$ & $-0.22(0.50)$ \\
\hline & $2 \mathrm{yrs}$ & $0.63(1.95)$ & $0.88(1.19)$ & $1.05(1.12)$ & $0.29(1.21)$ \\
\hline & 3 yrs & $0.10(2.75)$ & $1.85(1.77)$ & $1.67(2.00)$ & $0.35(1.88)$ \\
\hline & $6 \mathrm{yrs}$ & $-2.13(4.31)$ & $5.04(2.45)$ & $0.61(3.31)$ & $-2.64(4.22)$ \\
\hline \multirow[t]{4}{*}{ Investment } & $1 \mathrm{yr}$ & $-0.20(0.32)$ & $-0.31(0.36)$ & $-0.22(0.15)$ & $-0.55(0.31)$ \\
\hline & 2 yrs & $-1.07(0.72)$ & $-0.10(0.98)$ & $-0.57(0.25)$ & $-1.06(0.66)$ \\
\hline & $3 \mathrm{yrs}$ & $-2.24(0.93)$ & $0.52(1.57)$ & $-0.69(0.42)$ & $-1.43(0.81)$ \\
\hline & $6 \mathrm{yrs}$ & $-4.66(1.30)$ & $2.47(2.80)$ & $-1.15(0.77)$ & $-2.56(0.85)$ \\
\hline \multirow[t]{4}{*}{ Current Account } & $1 \mathrm{yr}$ & $0.33(0.44)$ & $-0.33(0.42)$ & $-0.77(0.45)$ & $-0.51(0.63)$ \\
\hline & $2 \mathrm{yrs}$ & $-0.23(0.88)$ & $-0.11(0.84)$ & $-1.42(0.81)$ & $-1.76(1.11)$ \\
\hline & $3 \mathrm{yrs}$ & $-0.80(1.32)$ & $-0.01(1.08)$ & $-2.03(1.26)$ & $-2.62(1.43)$ \\
\hline & $6 \mathrm{yrs}$ & $0.22(2.04)$ & $-0.49(1.50)$ & $-2.34(2.03)$ & $-4.06(2.04)$ \\
\hline \multirow[t]{4}{*}{ Interest Rate } & $1 \mathrm{yr}$ & $-1.53(1.41)$ & $-0.06(0.76)$ & $-0.90(0.69)$ & $-1.21(0.49)$ \\
\hline & $2 \mathrm{yrs}$ & $-3.83(2.75)$ & $0.17(1.71)$ & $-1.09(1.09)$ & $-1.42(1.10)$ \\
\hline & $3 \mathrm{yrs}$ & $-5.93(3.58)$ & $0.77(2.42)$ & $-0.47(1.20)$ & $-1.27(1.59)$ \\
\hline & $6 \mathrm{yrs}$ & $-6.09(4.60)$ & $4.41(3.58)$ & $0.85(1.77)$ & $-1.98(1.27)$ \\
\hline \multirow[t]{4}{*}{ Consumption } & $1 \mathrm{yr}$ & $0.01(0.68)$ & $-0.01(0.26)$ & $0.01(0.40)$ & $-0.00(0.30)$ \\
\hline & $2 \mathrm{yrs}$ & $0.01(1.60)$ & $-0.03(0.61)$ & $0.06(0.95)$ & $0.04(0.85)$ \\
\hline & $3 \mathrm{yrs}$ & $-0.01(2.65)$ & $-0.06(0.95)$ & $0.12(1.57)$ & 0.08 (1.39) \\
\hline & $6 \mathrm{yrs}$ & $-0.26(4.43)$ & $0.01(1.71)$ & $0.19(2.71)$ & $0.09(1.94)$ \\
\hline
\end{tabular}

Notes: Quantities are measured in output units; the size of shock is normalized so that the cumulated response of government spending after four quarters is one percent of trend output; standard errors obtained by bootstrap sampling are reported in parenthesis; the response of consumption is obtained by running the same VAR as the baseline specification, but by replacing investment with consumption. 
(a) Consumption

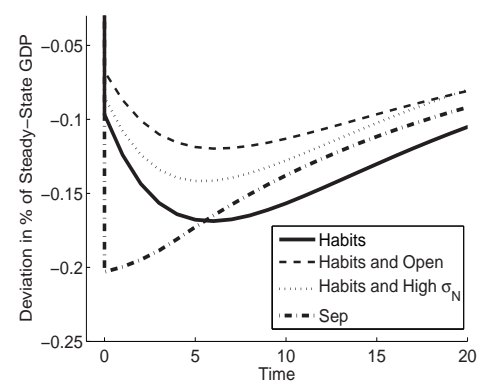

(d) Terms of Trade

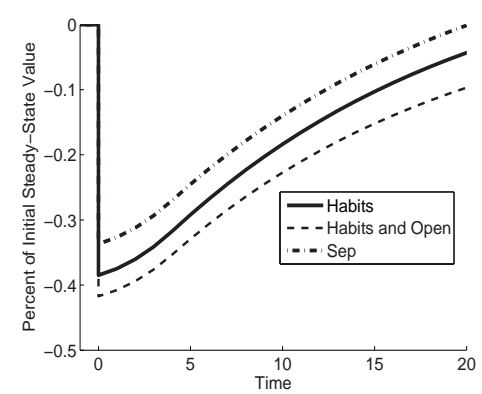

(b) Output

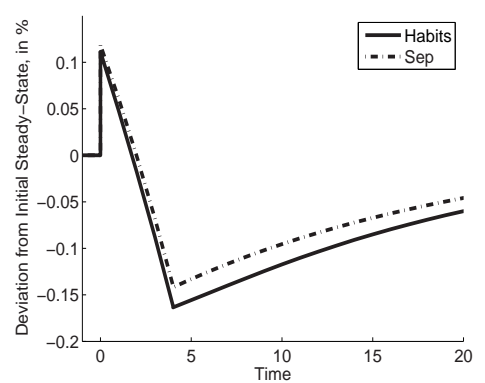

(e) Investment

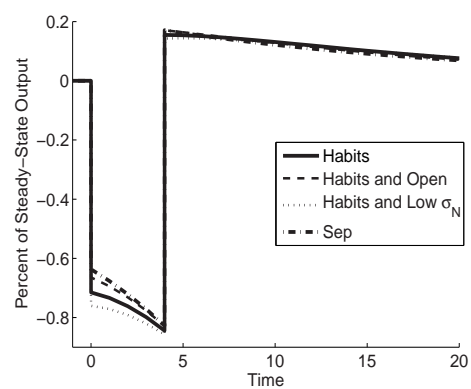

(c) Employment

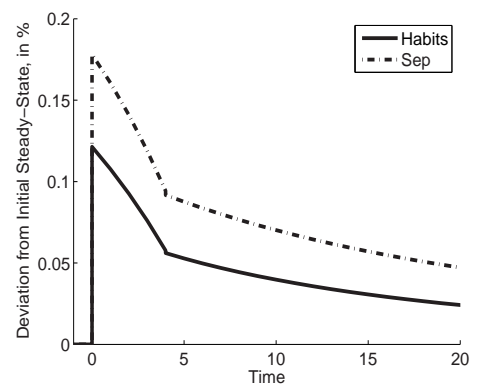

(f) Current Account

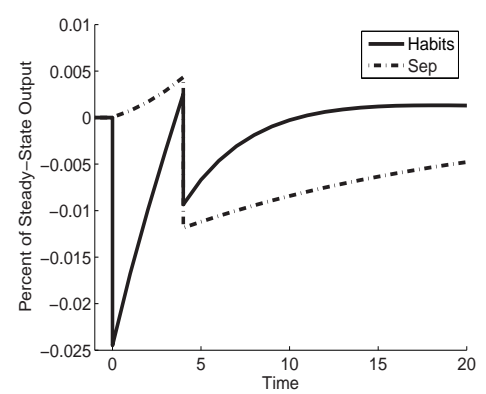

Figure 2: Computed Transitional Paths after a Temporary Fiscal Shock

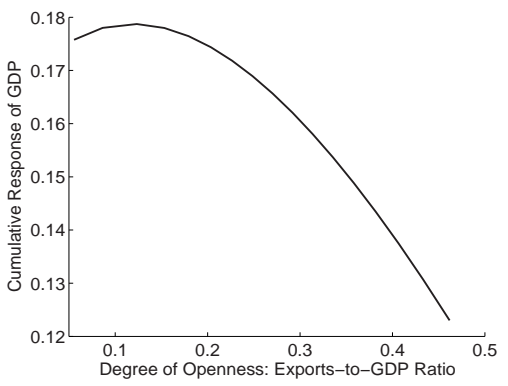

(a) Response of GDP against Trade Openness $(\gamma=0)$

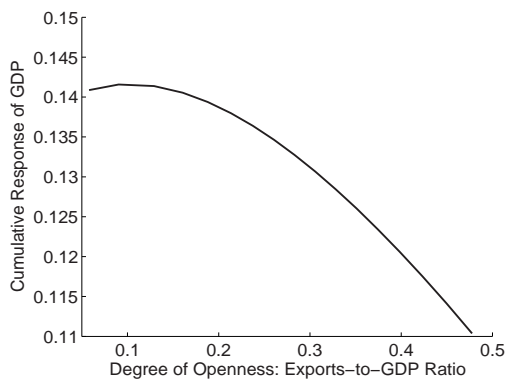

(b) Response of GDP against Trade Openness $(\gamma=0.8)$

Figure 3: Sensitivity of the Cumulative Response of GDP to Trade Openness 
宅

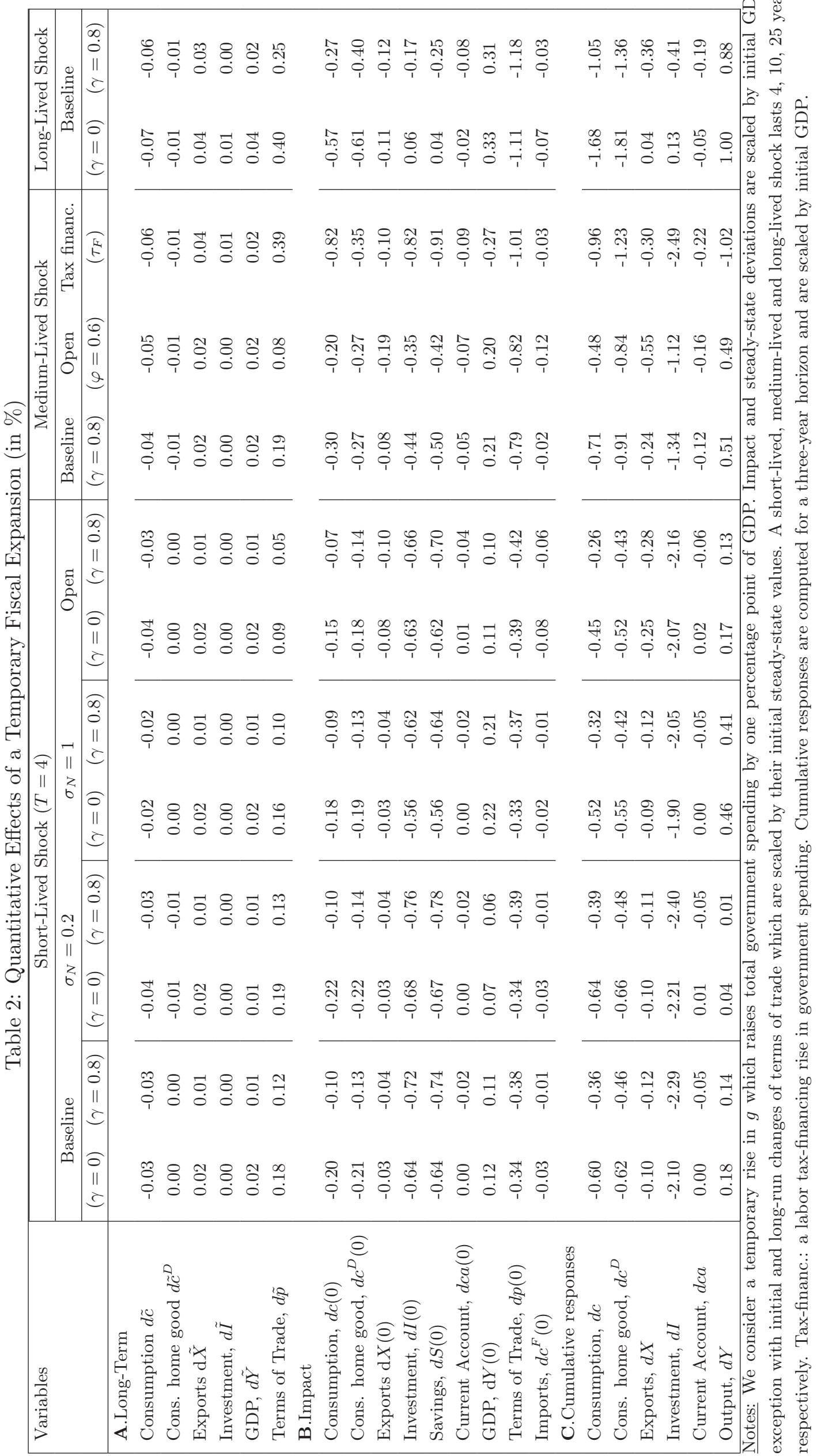




\section{HABIT FORMATION AND FISCAL TRANSMISSION IN OPEN ECONOMIES}

TECHNICAL APPENDIX

NOT INTENDED FOR PUBLICATION

AUGUST 2010

Olivier Cardi and Gernot Müller

Affiliation: ERMES, Université Panthéon Assas (Paris 2) and Department of Economics, Ecole Polytechnique

Address: Université Panthéon-Assas Paris 2, ERMES, 12 Place du Panthéon, 75230 Paris Cedex 05. France.

Phone: +33144418973

Fax: +33140518130

E-mail: olivier.cardi@u-paris2.fr

Affiliation: Bonn University and CEPR

Address: Department of Economics, University of Bonn, Lennéstr. 37, 53113 Bonn, Germany. E-mail: gernot.mueller@uni-bonn.de 


\section{A A Semi-Small Open Economy Model without Capital}

In this section, we construct a semi-small open economy model without capital accumulation to derive analytical expressions and discuss the role of habits in the fiscal policy transmission mechanism in the main text.

\section{A.1 Framework}

Households maximize the following objective function:

$$
U=\int_{0}^{\infty}\left\{\frac{1}{1-\epsilon}\left[\frac{c(t)}{(s(t))^{\gamma}}\right]^{1-\epsilon}-\gamma_{N} \frac{n(t)^{1+\epsilon_{N}}}{1+\epsilon_{N}}\right\} \exp (-\beta t) \mathrm{d} t
$$

subject to the flow budget constraint

$$
p(t) \dot{b}(t)=r^{\star} p(t) b(t)+w(t) n(t)-p_{c} c-T,
$$

and the accumulation equation of habits (5). The government finances government spending on the domestic good $g$ by levying lump-sum taxes $T$.

\section{Macroeconomic Equilibrium}

The macroeconomic equilibrium is described by the following set of equations:

$$
\begin{gathered}
u_{c}(c, s)+\sigma \xi=\frac{p_{c} \lambda}{p}, \\
v_{n}(n)=-\frac{\lambda}{p} w, \\
F_{n}(n)=w, \\
\dot{\lambda}=\lambda\left(\beta-r^{\star}\right), \\
\dot{\xi}=(\beta+\sigma) \xi-u_{s}(c, s), \\
F(n)=\left(1-\alpha_{c}\right) p_{c} c+X(p)+g,
\end{gathered}
$$

together with the accumulation equation of foreign assets (22), the accumulation equation of habits (5) and appropriate transversality conditions; $\left(1-\alpha_{c}\right) p_{c} c$ stands for the consumption in the domestic good.

Solving (23b) for labor yields $n=n(\bar{\lambda}, p)$. Substituting the short-run static solution for labor into the market-clearing condition for the home good (23f) and solving for the real exchange rate yields:

$$
p=\Pi\left(\bar{\lambda}, c, g^{D}\right),
$$

where

$$
\begin{gathered}
\Pi_{\bar{\lambda}} \equiv-\frac{F_{n} n_{\bar{\lambda}}}{F_{n} n_{p}-\Theta}>0, \\
\Pi_{c} \equiv \frac{\left(1-\alpha_{c}\right) p_{c}}{F_{n} n_{p}-\Theta}<0, \\
\Pi_{g D} \equiv \frac{1}{F_{n} n_{p}-\Theta}<0,
\end{gathered}
$$

with $\Theta \equiv \frac{X}{p}\left(\eta_{X}+\phi\left(1-\alpha_{c}\right) \frac{p c^{F}}{X}\right)>0$.

Differentiating (23a) with respect to time, substituting (5), (23e) and (24), eliminating $\xi$ by making use of (23a), yields the dynamic equation for real consumption:

$$
\dot{c}=-\Psi^{-1} \frac{p_{c} \bar{\lambda}}{p u_{c c}}\left(r^{\star}-\rho(c, s, p, \bar{\lambda})\right),
$$


where

$$
\Psi=1+\frac{p_{c} \bar{\lambda}}{p u_{c c} c}\left(1-\alpha_{c}\right) \frac{\Pi_{c} c}{p} .
$$

Linearizing (26) together with the accumulation equation of habits (5) around the steadystate, and denoting long-term values by a tilde, we obtain in a matrix form:

$$
(\dot{s}, \dot{c})^{T}=J(s(t)-\tilde{s}, c(t)-\tilde{c})^{T},
$$

where $J$ is given by

$$
J \equiv\left(\begin{array}{cc}
-\sigma & \sigma \\
\tilde{\Psi}^{-1} \frac{\beta+2 \sigma}{\tilde{u}_{c c}} \Gamma & (\beta+\sigma)
\end{array}\right)
$$

with

$$
\tilde{\Psi}=1+\frac{\beta+\sigma(1-\gamma)}{\epsilon(\beta+\sigma)} \frac{\tilde{c}^{D}\left(1-\alpha_{c}\right)}{\tilde{Y}\left[\chi\left(1-\alpha_{K}\right)+\frac{\tilde{\tilde{X}}}{\tilde{Y}} \nu_{X}+\frac{\tilde{p} \tilde{\tilde{C}}^{F}}{\tilde{Y}} \phi\left(1-\alpha_{c}\right)\right]}>1 .
$$

The determinant denoted by Det of the linearized $2 \times 2$ matrix (29) is unambiguously negative:

$$
\text { Det } \mathrm{J}=-\tilde{\Psi}^{-1} \frac{\sigma}{\epsilon}[\beta+\sigma(1-\gamma)]\left\{[\gamma+\epsilon(1-\gamma)]-\left(1-\alpha_{c}\right) \frac{\Pi_{c} \tilde{c}}{\tilde{p}}\right\}<0,
$$

where $0<\tilde{\Psi}^{-1}<1$. The trace denoted by $T r$ is given by:

$$
\operatorname{Tr} \mathrm{J}=\beta=r^{\star}>0 .
$$

The characteristic roots obtained from the $2 \times 2$ linearized matrix $J$ write as follows:

$$
\mu_{i} \equiv \frac{1}{2}\left\{\operatorname{Tr} J \pm \sqrt{(\operatorname{Tr} J)^{2}-4 \operatorname{Det} J}\right\} \gtrless 0, \quad i=1,2 .
$$

Since the system features one state variable, $s$, and one jump variable, $c$, the equilibrium yields a unique one-dimensional stable saddle-path. It is straightforward to show that setting $\gamma=0$ yields a stable root which simplifies to $\mu_{1}^{\gamma=0}=-\sigma$.

Stable solutions paths are given by:

$$
s(t)-\tilde{s}=B_{1} e^{\mu_{1} t}, \quad c(t)-\tilde{c}=\omega_{2}^{1} B_{1} e^{\mu_{1} t},
$$

where we normalized $\omega_{1}^{i}$ to unity. The eigenvector $\omega_{2}^{i}$ associated with eigenvalue $\mu_{i}$ is given by

$$
\omega_{2}^{i}=\left(\frac{\sigma+\mu_{i}}{\sigma}\right)>0, \quad i=1,2 .
$$

Eigenvector $\omega_{2}^{1}=\left(\frac{\sigma+\mu_{1}}{\sigma}\right)$ is positive if and only if:

$$
[\beta+\sigma(1-\gamma)][\gamma+\epsilon(1-\gamma)]<\epsilon(\beta+\sigma) .
$$

It can be shown that condition (36) is satisfied as long as $\epsilon>1$.

\section{A.2 Consumption, Habit Persistence, and Permanent Income}

Solving (22) and invoking the transversality condition yields:

$$
\int_{0}^{\infty} \frac{p_{c}}{p(\tau)} c(\tau) e^{-r^{\star}} \tau \mathrm{d} \tau=b(0)+W(0),
$$


where $W(0)$ denotes non-financial wealth, defined as the present discounted value of the future flow of real disposable income expressed in terms of the foreign good, i.e.

$$
W(0)=\int_{0}^{\infty}\left[\frac{w(\tau) n(\tau)-T}{p(\tau)}\right] e^{-r^{\star} \tau} \mathrm{d} \tau .
$$

Linearizing $\frac{p_{c}(p(t))}{p(t)} c(t)$ around the steady-state, substituting the stable solution for consumption $c(t)=\tilde{c}+\frac{\sigma+\mu_{1}}{\sigma}(s(t)-\tilde{s})$ into the intertemporal budget constraint, this enables us to derive the long-run level of real expenditure, $\tilde{c}$, which satisfies the intertemporal solvency condition given a stable adjustment:

$$
\tilde{c}=-\frac{\tilde{\Pi}}{\tilde{\Lambda}} \frac{r^{\star}\left(\sigma+\mu_{1}\right)}{\sigma} s_{0}+\frac{r^{\star}-\mu_{1}}{\tilde{\Lambda}} \frac{\tilde{p} r^{\star}\left[b_{0}+W(0)\right]}{p_{c}},
$$

where $\tilde{p} r^{\star}\left[b_{0}+W(0)\right] / p_{c}$ is the permanent income defined as the annuity value of financial and non financial wealth expressed in terms of the foreign good deflated by the consumption price index. Additionally, we set:

$$
\begin{aligned}
& \tilde{\Pi}=\left[1-\left(1-\alpha_{c}\right) \frac{\Pi_{c} \tilde{c}}{\tilde{p}}\right]=1+\frac{\left(1-\alpha_{c}\right) \frac{\tilde{c}^{D}}{\tilde{Y}}}{\left[\chi\left(1-\alpha_{K}\right)+\frac{\tilde{X}}{\tilde{Y}} \nu_{X}+\frac{\tilde{p} \tilde{c}^{F}}{\tilde{Y}} \phi\left(1-\alpha_{c}\right)\right]}>0, \\
& \tilde{\Lambda}=\left(r^{\star}-\mu_{1}\right)-\tilde{\Pi}\left(\frac{\sigma+\mu_{1}}{\sigma}\right) r^{\star}
\end{aligned}
$$

where $\tilde{\Pi}>1$.

Before deriving formal expressions of the marginal propensity to consume (MPC), we set the following assumption :

\section{Assumption $1 \tilde{\Pi}<\frac{r^{\star}-\mu_{1}}{r^{\star}}$.}

which in turn insures that $0<\tilde{\Lambda}<r^{\star}-\mu_{1}$. From an economic point of view, inequality $\tilde{\Pi}<\frac{r^{\star}-\mu_{1}}{r^{\star}}$ holds as long as the domestic content of total consumption expenditure $\left(1-\alpha_{c}\right)$ is small, and both the share of exports in GDP $\tilde{X} / \tilde{Y}$ and the import content of total consumption expenditure are large. Yet, as we shall see below, Assumption 1 holds even if the economy displays a small trade openness.

The term in front of the real permanent income $\frac{r^{\star}-\mu_{1}}{\tilde{\Lambda}}>0$ on the RHS of (37) represents the long-run MPC of the real permanent income. Setting $\gamma=0$ implies the multiplicative term reduces to unity so that the long-run MPC is equal to one. Unlike, relaxing time separability in utility implies that the long-MPC turns out to higher than one, at the condition that $\left(\sigma+\mu_{1}\right)>0$ which is satisfied.

Evaluating now the stable solution of $c(t)$ at time $t=0$, using the fact that $\tilde{s}=\tilde{c}$, and substituting (37), this enables us to derive the optimal initial level of real consumption:

$$
c(0)=\left(\frac{\sigma+\mu_{1}}{\sigma}\right)\left[1+\frac{\tilde{\Pi}}{\tilde{\Lambda}} \frac{r^{\star} \mu_{1}}{\sigma}\right] s_{0}-\frac{\mu_{1}}{\sigma} \frac{r^{\star}-\mu_{1}}{\tilde{\Lambda}} \frac{\tilde{p} r^{\star}\left[b_{0}+W(0)\right]}{p_{c}},
$$

where $\frac{r^{\star}-\mu_{1}}{\tilde{\Lambda}}>0$ represents the short-run MPC the real permanent income. As long as inequality $0<\tilde{\Pi}<\frac{r^{\star}-\mu_{1}}{r^{\star}}$ holds (see assumption (1)), optimal consumption at time $t=0$ is positively correlated with the initial stock of habits and the short-run marginal propensity to consume the real permanent income is smaller than unity. Notice that $0>\mu_{1}^{\gamma>0}>\mu_{1}^{\gamma=0}=-\sigma$. The reason is that without habits, dynamics do not degenerate but the adjustment towards the long-run equilibrium gets faster. Hence, the consumer without habits display a larger short-run marginal propensity to consume. 
In a small open economy model where the relative price of domestic goods is exogenous and thereby remains constant over time, we have $\tilde{\Psi}=\tilde{\Pi}=1$ and $\tilde{\Lambda}=-\frac{\mu_{1}}{\sigma}\left(\sigma+r^{\star}\right)$. Consequently, the short-run and long-run marginal propensities rewrite as follows:

$$
\begin{aligned}
\tilde{c} & =\frac{r^{\star}\left(\sigma+\mu_{1}\right)}{\mu_{1}\left(\sigma+r^{\star}\right)} s_{0}+\frac{\sigma\left(r^{\star}-\mu_{1}\right)}{\mu_{1}\left(\sigma+r^{\star}\right)} \frac{\tilde{p} r^{\star}\left[b_{0}+W(0)\right]}{p_{c}}, \\
c(0) & =\frac{\sigma+\mu_{1}}{\sigma+r^{\star}} s_{0}+\frac{r^{\star}-\mu_{1}}{\sigma+r^{\star}} \frac{\tilde{p} r^{\star}\left[b_{0}+W(0)\right]}{p_{c}} .
\end{aligned}
$$

From (40b), the condition for the short-term MPC to be smaller than unity is $\sigma+\mu_{1}>0$ which always holds as long as $\gamma>0$. In words, the short-run MPC is smaller with an exogenous $p$ than with an endogenous $p$. The reason is as follows. Along the transitional path, the real exchange depreciates which in turn implies a smoother real consumption adjustment (due to the the rise in the consumption-based real interest rate which compensates the high time preference rate). Such a consumption behavior is consistent with the intertemporal solvency condition as long as the consumption falls by a larger amount in the short-run than that prevailing with a real exchange rate constant over time. Without habits, $\mu_{1}^{\gamma=0}=-\sigma$ such that the short-run and long-run MPC coincide and are equal to unity.

\section{A.3 Short-Run Effects on Consumption and Current Account after a Tem- porary Fiscal Shock: Some Analytical Results}

In a first step, we solve the steady-state without the intertemporal solvency condition which allows us to express the steady-state levels of key economic variables in terms of the shadow value of wealth $(\bar{\lambda})$ and government spending $(g)$. For simplicity, we assume that the production function is linear with labor, i.e. $Y=n$. The steady-state is described by the following set of equations:

$$
\begin{gathered}
\tilde{c}=\left[\left(\frac{\beta+\sigma}{\beta+\sigma(1-\gamma)}\right) \frac{p_{c} \bar{\lambda}}{\tilde{p}}\right]^{-\nu}, \\
\tilde{n}=\left(\frac{1}{\gamma_{N}} \frac{\bar{\lambda}}{\tilde{p}}\right)^{\sigma_{N}}, \\
\tilde{n}=\tilde{c}^{D}+X(\tilde{p})+g \\
r^{\star} \tilde{b}+\frac{X(\tilde{p})}{\tilde{p}}-\tilde{c}^{F}=0 .
\end{gathered}
$$

We first solve (41a)-(41b) for consumption and labor :

$$
c=c(\bar{\lambda}, \tilde{p}), \quad n=n(\bar{\lambda}, \tilde{p}),
$$

where

$$
\begin{aligned}
& \hat{\tilde{c}}=\nu\left(1-\alpha_{c}\right) \hat{\tilde{p}}-\nu \hat{\bar{\lambda}}, \\
& \hat{\tilde{n}}=\sigma_{N} \hat{\bar{\lambda}}-\sigma_{N} \hat{\tilde{p}} .
\end{aligned}
$$

where we denote by a hat the rate of change of variable $x=c, n$.

Using the Shephard's Lemma, intra-temporal allocations between domestic goods and foreign goods are: $c^{F}=p_{c}^{\prime} c$ and $c^{D}=\left[p_{c}-p p_{c}^{\prime}\right] c$ and substituting (42), we solve for consumption in the domestic and foreign goods:

$$
c^{D}=c^{D}(\bar{\lambda}, \tilde{p}), \quad c^{F}=c^{F}(\bar{\lambda}, \tilde{p}),
$$

where the partial derivatives are given by

$$
\begin{aligned}
\hat{\tilde{c}}^{D} & =\left[\phi \alpha_{c}+\left(1-\alpha_{c}\right) \nu\right] \hat{\tilde{p}}-\nu \hat{\bar{\lambda}}, \\
\hat{\tilde{c}}^{F} & =\left(1-\alpha_{c}\right)(\phi-\nu) \hat{\tilde{p}}-\nu \hat{\bar{\lambda}},
\end{aligned}
$$


where we assumed that $\nu<\phi$ since empirical evidence suggest that $\nu<1$.

Substituting (44) into the market-clearing condition (41c) and the zero current account equation (41d), and differentiating, we get:

$$
\begin{aligned}
& \hat{\tilde{p}}=\frac{\left(\sigma_{N}+\nu\left(1-\alpha_{c}\right) \omega_{c}\right) \hat{\bar{\lambda}}-(\mathrm{d} g / \tilde{Y})}{\left[\sigma_{N}+\left[\phi \alpha_{c}+\left(1-\alpha_{c}\right) \nu\right]\left(1-\alpha_{c}\right) \omega_{C}+\omega_{X} \eta_{X}\right]}, \\
& \hat{\tilde{b}}=-\frac{\left[\omega_{X}\left(\eta_{X}-1\right)+\alpha_{c} \omega_{c}\left(1-\alpha_{c}\right)(\phi-\nu)\right] \hat{\tilde{p}}+\alpha_{c} \omega_{c} \nu \hat{\bar{\lambda}}}{\omega_{B}},
\end{aligned}
$$

where $\omega_{c}=p_{c} \tilde{c} / \tilde{Y}$ and $\omega_{B}=r^{\star} \tilde{p} \tilde{b} / \tilde{Y}$.

Inserting (46a) into (43) and (46b), steady-state can be solved for consumption, employment, the terms of trade and the stock of foreign bonds:

$$
\begin{aligned}
\tilde{c} & =c(\bar{\lambda}, g), \\
\tilde{n} & =n(\bar{\lambda}, g), \\
\tilde{p} & =p(\bar{\lambda}, g), \\
\tilde{b} & =b(\bar{\lambda}, g),
\end{aligned}
$$

with

$$
\begin{aligned}
& \frac{\hat{\tilde{c}}}{\overline{\bar{\lambda}}}=-\frac{\omega_{B} \nu}{G}\left\{\alpha_{c} \sigma_{N}+\omega_{c}\left(1-\alpha_{c}\right) \alpha_{c} \phi+\omega_{X} \nu_{X}\right\}<0, \\
& \frac{\hat{\tilde{c}}}{\frac{d g}{\tilde{Y}}}=-\frac{\omega_{B} \nu\left(1-\alpha_{c}\right)}{G}<0, \\
& \frac{\hat{\tilde{p}}}{\hat{\bar{\lambda}}}=\frac{\omega_{B}}{G}\left\{\sigma_{N}+\nu\left(1-\alpha_{c}\right) \omega_{c}\right\}>0, \\
& \frac{\hat{\tilde{p}}}{\frac{d g}{\bar{Y}}}=-\frac{\omega_{B}}{G}<0 \text {, } \\
& \frac{\hat{\tilde{b}}}{\overline{\hat{\lambda}}}=-\frac{1}{G}\left\{\left(\sigma_{N}+\nu \omega_{c}\right)\left[\omega_{X}\left(\nu_{X}-1\right)+\omega_{c}\left(1-\alpha_{c}\right) \alpha_{c}(\phi-\nu)\right]\right. \\
& \left.+\nu \alpha_{c} \omega_{c}\left[\sigma_{N}+\omega_{c} \nu\left(1-\alpha_{c}\right)+\omega_{X}\right]\right\}<0, \\
& \frac{\hat{\tilde{b}}}{\frac{d g}{\tilde{Y}}}=\frac{\omega_{X}\left(\nu_{X}-1\right)+\omega_{c}\left(1-\alpha_{c}\right) \alpha_{c}(\phi-\nu)}{G}>0 \text {, }
\end{aligned}
$$

and

$$
G \equiv \omega_{B}\left\{\sigma_{N}+\left[\nu\left(1-\alpha_{c}\right)+\phi \alpha_{c}\right] \omega_{c}\left(1-\alpha_{c}\right)+\omega_{X} \nu_{X}\right\}>0 .
$$

Substituting the short-run static solution for the terms of trade $p=\Pi(\bar{\lambda}, c, g)$ (see eq. (24)) into the dynamic equation for the current account $\dot{b}=r^{\star} b+X(p) / p-c^{F}$, linearizing around the steady-state, substituting formal solutions, and solving we get:

$$
b(t)=\tilde{b}+\left[\left(b_{0}-\tilde{b}\right)-\tilde{\Gamma}_{1} A_{1}-\tilde{\Gamma}_{2} A_{2}\right] e^{r^{\star} t}+\tilde{\Gamma}_{1} A_{1} e^{\mu_{1} t}+\tilde{\Gamma}_{2} A_{2} e^{\mu_{2} t},
$$

where we set

$$
\tilde{\Gamma}_{1}=\frac{\left(\tilde{\Omega} \Pi_{c}-p_{c}^{\prime}\right) \omega_{2}^{1}}{\mu_{1}-r^{\star}}>0, \quad \tilde{\Gamma}_{2}=\frac{\left(\tilde{\Omega} \Pi_{c}-p_{c}^{\prime}\right) \omega_{2}^{2}}{\mu_{2}-r^{\star}}<0,
$$

with $\omega_{2}^{1}>0, \omega_{2}^{2}>0, \tilde{\Omega}=\frac{\tilde{X}}{\tilde{p}^{2}}\left[\left(\eta_{X}-1\right)+\frac{\tilde{p} \tilde{c}^{F}}{\tilde{X}} \phi\left(1-\alpha_{c}\right)\right]>0$ and

$$
\tilde{\Omega} \tilde{\Pi}_{c}-p_{c}^{\prime}=-\frac{p_{c}}{\tilde{p}}\left\{\frac{\omega_{X}\left(\eta_{X}-1\right)+\phi\left(1-\alpha_{c}\right) \alpha_{c} \omega_{c}+\alpha_{c}\left(\sigma_{N}+\omega_{X}\right)}{\sigma_{N}+\omega_{X} \eta_{X}+\phi\left(1-\alpha_{c}\right) \alpha_{c} \omega_{c}}\right\}<0 .
$$


Invoking the transversality condition, the intertemporal solvency condition writes as follows:

$$
\tilde{b}-b_{0}=\tilde{\Gamma}_{1}\left(\tilde{s}-s_{0}\right) .
$$

The second step consists to determine the equilibrium change of $\bar{\lambda}_{i}$ by taking the total differential of the intertemporal solvency condition (53):

$$
\left(b_{\bar{\lambda}}-\tilde{\Gamma}_{1} c_{\bar{\lambda}}\right) \mathrm{d} \bar{\lambda}=\mathrm{d} b_{T}-\tilde{\Gamma}_{1} \mathrm{~d} s_{T}-\left(b_{g}-\tilde{\Gamma}_{1} c_{g}\right) \mathrm{d} g
$$

from which we derive

$$
\lambda_{g} \equiv \frac{\mathrm{d} \bar{\lambda}_{i}}{\mathrm{~d} p_{i}}=-\frac{b_{g}-\tilde{\Gamma}_{1} c_{g}}{b_{\bar{\lambda}}-\tilde{\Gamma}_{1} c_{\bar{\lambda}}}>0 .
$$

We solve the system written in a matrix form for the constants and the change in the equilibrium value of the marginal utility of wealth:

$$
\left(\begin{array}{cccc}
\tilde{\Gamma}_{1} & \tilde{\Omega}_{1} & 0 & b_{\bar{\lambda}} \\
1 & 1 & 0 & c_{\bar{\lambda}} \\
e^{\mu_{1} T} & e^{\mu_{2} T} & -e^{\mu_{1} T} & 0 \\
\omega_{2}^{1} e^{\mu_{1} T} & \omega_{2}^{2} e^{\mu_{2} T} & -\omega_{2}^{1} e^{\mu_{1} T} & 0
\end{array}\right)\left(\begin{array}{c}
A_{1} \\
A_{2} \\
B_{1} \\
\mathrm{~d} \bar{\lambda}
\end{array}\right)=\left(\begin{array}{c}
-\Phi_{1} \\
-c_{g} \mathrm{~d} g \\
-c_{g} \mathrm{~d} g \\
-c_{g} \mathrm{~d} g
\end{array}\right)
$$

where the determinant $E$ writes as:

$$
E \equiv-\left(b_{\bar{\lambda}}-\tilde{\Gamma}_{1} c_{\bar{\lambda}}\right)\left(\omega_{2}^{2}-\omega_{2}^{1}\right) e^{r^{\star} T}>0,
$$

and $\tilde{\Gamma}_{1}$ is given by $(51)$ and

$$
\begin{aligned}
& \tilde{\Omega}_{1}=\tilde{\Gamma}_{2}+\left(\tilde{\Gamma}_{1}-\tilde{\Gamma}_{2}\right) e^{\left(\mu_{2}-r^{\star}\right) T} \\
& \Phi_{1}=\left[b_{g}-\left(b_{g}-\tilde{\Gamma}_{1} c_{g}\right) e^{-r^{\star} T}\right] \mathrm{d} g .
\end{aligned}
$$

Solving (56) yields:

$$
\begin{aligned}
\left.\frac{\mathrm{d} \bar{\lambda}}{\mathrm{d} g}\right|_{t e m p} & =\lambda_{g}\left(1-e^{-r^{\star} T}\right)+\frac{c_{g}}{\left(b_{\bar{\lambda}}-\tilde{\Gamma}_{1} c_{\bar{\lambda}}\right)} \frac{\mu_{1}}{\sigma} \frac{\left(\Gamma_{1}-\Gamma_{2}\right)}{\left(\omega_{2}^{2}-\omega_{2}^{1}\right)}\left(e^{-\mu_{2} T}-e^{-r^{\star} T}\right) \\
\frac{A_{1}}{\mathrm{~d} g} & =-\left.\frac{\mathrm{d} \tilde{c}_{1}}{\mathrm{~d} g}\right|_{t e m p}-\frac{A_{2}}{\mathrm{~d} g}=-\left.c_{\bar{\lambda}} \frac{\mathrm{d} \bar{\lambda}}{\mathrm{d} g}\right|_{t e m p}-c_{g}-\frac{A_{2}}{\mathrm{~d} g}=-\left.\frac{\mathrm{d} \tilde{c}}{\mathrm{~d} g}\right|_{t e m p}-c_{g}-\frac{A_{2}}{\mathrm{~d} g}, \\
\frac{A_{2}}{\mathrm{~d} g} & =c_{g} e^{-\mu_{2} T} \frac{\omega_{2}^{1}-1}{\omega_{2}^{2}-\omega_{2}^{1}}=c_{g} e^{-\mu_{2} T} \frac{\mu_{1}}{\mu_{2}-\mu_{1}}
\end{aligned}
$$

where we used the fact that $\mu_{1}-r^{\star}=-\mu_{2}$ and the following expressions:

$$
\begin{aligned}
\omega_{2}^{2}-\omega_{2}^{1} & =\frac{\mu_{2}-\mu_{1}}{\sigma}, \\
\tilde{\Gamma}_{1}-\tilde{\Gamma}_{2} & =\frac{\tilde{\Omega} \Pi_{c}-p_{c}^{\prime}}{\sigma \mu_{1} \mu_{2}}\left(\mu_{2}-\mu_{1}\right)\left(\sigma+r^{\star}\right), \\
\frac{\mu_{1}}{\sigma} \frac{\left(\Gamma_{1}-\Gamma_{2}\right)}{\left(\omega_{2}^{2}-\omega_{2}^{1}\right)} & =\frac{\sigma+r^{\star}}{r^{\star}-\mu_{1}}\left(\tilde{\Omega} \Pi_{c}-p_{c}^{\prime}\right)<0 .
\end{aligned}
$$

Setting $t=0$ into the formal solution for consumption and differentiating w.r.t. $g$ yields the initial jump of real consumption following an expansionary budget policy falling on the domestic good:

$$
\begin{aligned}
\left.\frac{\mathrm{d} c(0)}{\mathrm{d} g}\right|_{t e m p} & =\left.\frac{\mathrm{d} \tilde{c}_{1}}{\mathrm{~d} g}\right|_{t e m p}+\omega_{2}^{1} \frac{A_{1}}{\mathrm{~d} g}+\omega_{2}^{2} \frac{A_{2}}{\mathrm{~d} g} \\
& =-\frac{\mu_{1}}{\sigma}\left[\left.\frac{\mathrm{d} \tilde{c}}{\mathrm{~d} g}\right|_{t e m p}+c_{g}\left(1-e^{-\mu_{2} T}\right)\right]
\end{aligned}
$$


Eq. (61) corresponds to eq. (15) in the text.

Let evaluate the long-run change of real consumption after a temporary rise in government spending. At this end, we estimate useful expressions. Plugging the short-run static solution for the terms of trade which obviously holds at the steady-state, i.e. $\tilde{p}=\Pi(\bar{\lambda}, \tilde{c}, g)$, together with (47a), into the long-run current account equation $r^{\star} \tilde{b}+\frac{X(\tilde{p})}{\tilde{p}}-p_{c}^{\prime} \tilde{c}$, and differentiating w.r.t. $\bar{\lambda}$, we get: $r^{\star} b_{\bar{\lambda}}+\left(\tilde{\Omega}_{\Pi_{c}}-p_{c}^{\prime}\right) c_{\bar{\lambda}}+\tilde{\Omega}_{\bar{\Pi}} \tilde{\Pi}_{\bar{\lambda}}=0$. Using this equation to rewrite $b_{\bar{\lambda}}+\tilde{\Gamma}_{1} c_{\bar{\lambda}}$, we obtain:

$$
b_{\bar{\lambda}}+\tilde{\Gamma}_{1} c_{\bar{\lambda}}=\frac{c_{\bar{\lambda}}}{r^{\star}}\left[\left(\tilde{\Omega} \tilde{\Pi}_{c}-p_{c}^{\prime}\right) \frac{\mu_{1}\left(\sigma+r^{\star}\right)}{\sigma\left(r^{\star}-\mu_{1}\right)}-\tilde{\Omega} \frac{\tilde{\Pi}_{\bar{\lambda}}}{c_{\bar{\lambda}}}\right]<0,
$$

where $\tilde{\Omega}>0, \tilde{\Pi}_{c}<0, \tilde{\Pi}_{\bar{\lambda}}>0, c_{\bar{\lambda}}<0$.

The initial jump of the marginal utility of wealth $\bar{\lambda}$ can be rewritten by using (62):

$$
\left.\frac{\mathrm{d} \bar{\lambda}}{\mathrm{d} g}\right|_{t e m p}=\lambda_{g}\left(1-e^{-r^{\star} T}\right)+r^{\star} \frac{c_{g}}{c_{\bar{\lambda}}} \tilde{\chi}\left(e^{-r^{\star} T}-e^{-\mu_{2} T}\right)>0
$$

where we set:

$$
\tilde{\chi}=-\frac{\frac{\sigma+r^{\star}}{r^{\star}-\mu_{1}}\left(\tilde{\Omega} \tilde{\Pi}_{c}-p_{c}^{\prime}\right)}{\left[\left(\tilde{\Omega} \tilde{\Pi}_{c}-p_{c}^{\prime}\right) \frac{\mu_{1}\left(\sigma+r^{\star}\right)}{\sigma\left(r^{\star}-\mu_{1}\right)}-\tilde{\Omega} \frac{\tilde{\Pi}_{\bar{\lambda}}}{c_{\bar{\lambda}}}\right]}>0 .
$$

From expression (63), an expansionary budget policy exerts on $\bar{\lambda}$ two influences that work in the same direction. The wealth effect comes from the fall in the real disposable income which reduces the present value of wealth. The first term on the right-hand side of (63) indicates that the change of the marginal utility of wealth equals the change after a permanent government spending shock, $\lambda_{g}$, scaled-down by the term $0<\left(1-e^{-r^{\star} T}\right)<1$. The second works in the same direction of the wealth effect and reflects the effect of the relative price on consumption originating from the change in the terms of trade. Over period 2, say once the policy is removed, the terms of trade deteriorate as the drop in government spending triggers an excess of supply which must be eliminated by a rise in the relative price $p$. This terms of trade deterioration reduces the marginal utility of wealth measured in terms of the domestic good $p_{c} \bar{\lambda} / p$ which requires an additional rise in $\bar{\lambda}$ for the intertemporal solvency condition to hold (i.e. to moderate the rise in consumption). Interestingly, the second term increases as habit persistence gets stronger. as:

Using the fact that $\left.\frac{\mathrm{d} \tilde{c}}{\mathrm{~d} g}\right|_{t e m p}=\left.c_{\bar{\lambda}} \frac{\mathrm{d} \bar{\lambda}}{\mathrm{d} g}\right|_{t e m p}$, the long-term change of real consumption writes

$$
\left.\frac{\mathrm{d} \tilde{c}}{\mathrm{~d} g}\right|_{\text {temp }}=c_{\bar{\lambda}} \lambda_{g}\left(1-e^{-r^{\star} T}\right)+r^{\star} c_{g} \tilde{\chi}\left(e^{-r^{\star} T}-e^{-\mu_{2} T}\right)<0 .
$$

Eq. (65) corresponds to eq. (16) in the text. As government spending returns back to its initial level, the long-term change in real consumption is mainly determined by the change in the equilibrium value of the marginal utility of wealth.

Differentiating the formal solution (50) for the stock of traded bonds $b(t)$, substituting (59b), we obtain the adjustment of the current account $c a(t)$ :

$$
c a(t)=-r^{\star}\left[\left.\frac{\mathrm{d} \tilde{b}_{1}}{\mathrm{~d} g}\right|_{t e m p}-\left.\tilde{\Gamma}_{1} \frac{\mathrm{d} \tilde{c}_{1}}{\mathrm{~d} g}\right|_{t e m p}+A_{2}\left(\tilde{\Gamma}_{2}-\tilde{\Gamma}_{1}\right)\right] e^{r^{\star} t}+\mu_{1} \tilde{\Gamma}_{1} A_{1} e^{\mu_{1} t}+\mu_{2} \tilde{\Gamma}_{2} A_{2} e^{\mu_{2} t} .
$$

Substituting (59c), and using the fact that

$$
\left.\frac{\mathrm{d} \tilde{b}_{1}}{\mathrm{~d} g}\right|_{t e m p}=\left.\frac{\mathrm{d} \tilde{b}}{\mathrm{~d} g}\right|_{t e m p}+b_{g}=\left.b_{\bar{\lambda}} \frac{\mathrm{d} \bar{\lambda}}{\mathrm{d} g}\right|_{t e m p}+b_{g}
$$


together with $-\lambda_{g}\left(b_{\bar{\lambda}}-\tilde{\Gamma}_{1} c_{\bar{\lambda}}\right)=\left(b_{g}-\tilde{\Gamma}_{1} c_{g}\right)$ we can estimate

$$
\begin{aligned}
& \left.\frac{\mathrm{d} \tilde{b}_{1}}{\mathrm{~d} g}\right|_{t e m p}-\left.\tilde{\Gamma}_{1} \frac{\mathrm{d} \tilde{c}_{1}}{\mathrm{~d} g}\right|_{t e m p}+A_{2}\left(\tilde{\Gamma}_{2}-\tilde{\Gamma}_{1}\right), \\
= & \left(b_{\bar{\lambda}}-\tilde{\Gamma}_{1} c_{\bar{\lambda}}\right)\left[\left.\frac{\mathrm{d} \bar{\lambda}}{\mathrm{d} g}\right|_{t e m p}-\lambda_{g}\right]+c_{g} e^{-\mu_{2} T} \frac{\mu_{1}}{\mu_{2}-\mu_{1}}\left(\tilde{\Gamma}_{2}-\tilde{\Gamma}_{1}\right), \\
= & {\left[\left(b_{g}-\tilde{\Gamma}_{1} c_{g}\right)-c_{g} \frac{\mu_{1}\left(\tilde{\Gamma}_{1}-\tilde{\Gamma}_{2}\right)}{\mu_{2}-\mu_{1}}\right] e^{-r^{\star} T} \gtrless 0, }
\end{aligned}
$$

where

$$
\tilde{\Gamma}_{1}+\frac{\mu_{1}\left(\tilde{\Gamma}_{1}-\tilde{\Gamma}_{2}\right)}{\mu_{2}-\mu_{1}}=\frac{\tilde{\Omega} \tilde{\Pi}_{c}-p_{c}^{\prime}}{\sigma}<0 .
$$

Hence (68) can be rewritten as follows:

$$
\left[b_{g}-\frac{\tilde{\Omega} \tilde{\Pi}_{c}-p_{c}^{\prime}}{\sigma} c_{g}\right] \gtrless 0 .
$$

We cannot determine the sign of the expression analytically. Yet, in a small open economy model, the relative price is exogenous so that $c_{g}=0$ and expression reduces to $b_{g}>0$. This term reflects the standard smoothing effect through the decumulation of traded bonds. The second offsetting term reflects the rise in the consumption-bases real interest rate as the terms of trade deteriorate, i.e. $\dot{p}>0$ which induces agents to lower their real consumption.

Setting $t=0$ into (66) yields the initial reaction of the current account:

$$
c a(0)=-r^{\star}\left[b_{g}-\frac{\tilde{\Omega} \tilde{\Pi}_{c}-p_{c}^{\prime}}{\sigma} c_{g}\right] e^{-r^{\star} T} \mathrm{~d} g+\mu_{1} \tilde{\Gamma}_{1} A_{1}+\mu_{2} \tilde{\Gamma}_{2} A_{2} .
$$

The sign of the expression in brackets is ambiguous and decreases with the shock's persistence. The term $b_{g}$ reflects the smoothing behavior which induces agents to decumulate foreign bonds. The reason is that a temporary shock results in a larger impact on current than on permanent income, and this gap gets larger as the perturbation is short-living. Therefore, the current account will be more affected the shorter-lasting is the perturbation. Yet, in a two-good model where the relative price is endogenous, a second effect reflected by the term $c_{g}$ counteracts the smoothing behavior. More precisely, the terms of trade deterioration $\dot{p}<0$ raises the consumption-based real interest rate which provides an incentive to reallocate real expenditure towards the future. In a one-good open economy model or a two-good framework where the terms of trade are exogenous, the term $c_{g}$ vanishes so that the expression is unambiguously negative. Additionally, we show below that the second expression on the RHS is unambiguously negative. The first term $\mu_{1} \tilde{\Gamma}_{1} A_{1}<0$ reflects the fact that habit-forming consumers facing a drop in their disposable income wish to sustain their original standard of living. Hence, they disave by decumulating foreign bonds. This term shows up after both a permanent and a temporary shock but vanishes in a model with time separable preferences. The second term $\mu_{2} \tilde{\Gamma}_{2} A_{2}<0$ is negative and amplifies the current account deficit triggered by the habit-forming behavior. This term would vanish in a one-good model. It reflects the fact that the increase in the relative price $p$, while government spending is temporarily high, raises consumption (by lowering $\left.p_{c} b a r \lambda / p\right)$ which in turn induces an increase in consumption that deteriorates the current account.

We now estimate the following term by substituting (59b) and (59c):

$$
\begin{aligned}
& \mu_{1} \tilde{\Gamma}_{1} A_{1}+\mu_{2} \tilde{\Gamma}_{2} A_{2}, \\
= & -\mu_{1} \tilde{\Gamma}_{1}\left[\left.\frac{\mathrm{d} \tilde{c}}{\mathrm{~d} g}\right|_{t e m p}+c_{g}\right] \mathrm{d} g+c_{g} e^{-\mu_{2} T} \frac{\mu_{1}}{\mu_{2}-\mu_{1}}\left[\mu_{2} \tilde{\Gamma}_{2}-\mu_{1} \tilde{\Gamma}_{1}\right] \mathrm{d} g<0,
\end{aligned}
$$


where

$$
\mu_{2} \tilde{\Gamma}_{2}-\mu_{1} \tilde{\Gamma}_{1}=\frac{\tilde{\Omega} \tilde{\Pi}_{c}-p_{c}^{\prime}}{\sigma \mu_{1} \mu_{2}}\left(\mu_{1}-\mu_{2}\right)\left\{r^{\star}\left(\sigma+r^{\star}\right)-\mu_{1} \mu_{2}\right\}<0
$$

\section{A.4 Initial Reaction of Consumption and the Degree of Openness}

Linearize first the first-order condition $u_{c}+\sigma \xi=\frac{p_{c}}{p} \lambda$ around the steady-state:

$$
u_{c c}(c(t)-\tilde{c})+u_{c s}(s(t)-\tilde{s})+\sigma(\xi(t)-\tilde{\xi})=-\frac{\bar{\lambda} p_{c}\left(1-\alpha_{c}\right)}{\tilde{p}^{2}}(p(t)-\tilde{p}) .
$$

Evaluating the above expression at time $t=0$ and totally differentiating,

$$
\mathrm{d} c(0)+\sigma \mathrm{d} \xi(0)=-\frac{\bar{\lambda} p_{c}\left(1-\alpha_{c}\right)}{\tilde{p}^{2}} \mathrm{~d} p(0)+\frac{p_{c}}{\tilde{p}} d \bar{\lambda}
$$

where we used the fact that $u_{c c} d \tilde{c}+u_{c s} d \tilde{s}+\sigma d \tilde{\xi}+\frac{\bar{\lambda} p_{c}\left(1-\alpha_{c}\right)}{\tilde{p}^{2}} d \tilde{p}=\frac{p_{c}}{\tilde{p}} d \bar{\lambda}$, and $s(0)=s_{0}$. Solving the differential equation $\dot{\xi}=(\beta+\sigma) \xi-u_{s}(c, s)$ for $\xi(t)$ and invoking the transversality condition, we get:

$$
\xi(t)=\int_{0}^{\infty} u_{s} e^{-(\beta+\sigma)(\tau-t)} \mathrm{d} \tau .
$$

Linearizing the above expression, evaluating at time $t=0$, solving and totally differentiating, we have:

$$
\mathrm{d} \xi(0)=\frac{u_{c s}}{\beta+\sigma} \mathrm{d} c(0)
$$

Substituting eq. (75) into eq. (73) yields:

$$
\left[u_{c c}+\frac{\sigma}{\beta+\sigma} u_{c s}\right] \mathrm{d} c(0)=-\frac{\bar{\lambda} p_{c}\left(1-\alpha_{c}\right)}{\tilde{p}^{2}} \mathrm{~d} p(0)+\frac{p_{c}}{\tilde{p}} d \bar{\lambda}
$$

Using the iso-elastic form for the utility function, we have:

$$
\left[u_{c c}+\frac{\sigma}{\beta+\sigma} u_{c s}\right]=-\frac{\epsilon[\beta+\sigma(1-\gamma)]+\sigma \gamma}{\beta+\sigma} \tilde{c}^{-1} \tilde{c}^{-[\gamma+\epsilon(1-\gamma)]}
$$

Substituting this expression into (76), we have:

$$
\frac{\mathrm{d} c(0)}{\tilde{c}}=\tilde{c}^{[\gamma+\epsilon(1-\gamma)]} \frac{\beta+\sigma}{\epsilon[\beta+\sigma(1-\gamma)]+\sigma \gamma} \frac{\bar{\lambda} p_{c}\left(1-\alpha_{c}\right)}{\tilde{p}} \frac{\mathrm{d} p(0)}{\tilde{p}}-\frac{\beta+\sigma(1-\gamma)}{\epsilon[\beta+\sigma(1-\gamma)]+\sigma \gamma} \frac{\mathrm{d} \bar{\lambda}}{\bar{\lambda}} .
$$

Using the expression of the steady-state value of real consumption $\tilde{c}^{-[\gamma+\epsilon(1-\gamma)]}=\frac{\beta+\sigma}{\beta+\sigma(1-\gamma)} \frac{p_{c} \bar{\lambda}}{\tilde{p}}$, the initial rate of change of real consumption can be expressed as:

$$
\frac{\mathrm{d} c(0)}{\tilde{c}}=\frac{\beta+\sigma(1-\gamma)}{\epsilon[\beta+\sigma(1-\gamma)]+\sigma \gamma}\left(1-\alpha_{c}\right) \frac{\mathrm{d} p(0)}{\tilde{p}}-\frac{\beta+\sigma(1-\gamma)}{\epsilon[\beta+\sigma(1-\gamma)]+\sigma \gamma} \frac{\mathrm{d} \bar{\lambda}}{\bar{\lambda}} .
$$

Eq. (78) corresponds to eq. (18) in the text. The term $\frac{\beta+\sigma(1-\gamma)}{\epsilon[\beta+\sigma(1-\gamma)]+\sigma \gamma}$ on the RHS of (78) in front of the rate of change of the terms of trade is a decreasing function of $\gamma$. Hence, as $\gamma$ gets closer to unity, real consumption falls by a smaller amount for a given initial terms of trade improvement $\frac{\mathrm{d} p(0)}{\tilde{p}}<0$. Additionally, an increase in trade openness (i.e. a decrease in $\left.\left(1-\alpha_{c}\right)\right)$ moderates the the initial drop of consumption following a fall in $p$. 


\section{A.5 Initial Reaction of the Current Account and the Degree of Openness}

Linearizing the stock of foreign bonds $p(t) b(t)$ around the steady-state, we have:

$$
p(t) b(t)=\tilde{p} \tilde{b}+\tilde{p}(b(t)-\tilde{b})+\tilde{b}(p(t)-\tilde{p}) .
$$

Differentiating w.r.t. time, denoting $c a^{\prime}(t)=\tilde{p} c a(t)+\tilde{b} \dot{p}(t)=\tilde{p} \dot{b}(t)+\tilde{p} \dot{p}(t)$ and remembering that $c a(t)=r^{\star} b(t)+\frac{X(t)}{p(t)}-c^{F}(t)$, the current account $\tilde{p} c a(t)$ measured in terms of the domestic good can be written as follows:

$$
c a^{\prime}(t)=\tilde{p} r^{\star} b(t)+\tilde{p}\left[\frac{X(t)}{p(t)}-c^{F}(t)\right]+\tilde{b} \dot{p}(t) .
$$

Linearization of $c a(t)=r^{\star} b(t)+\tilde{p}\left[\frac{X(t)}{p(t)}-c^{F}(t)\right]$ around the steady-state and multiplying by $\tilde{p}$ yields:

$$
\tilde{p} \dot{b}(t)=\tilde{p} r^{\star}(b(t)-\tilde{b})+\left[\tilde{X}\left(\eta_{X}-1\right)+\phi\left(1-\alpha_{c}\right) \tilde{p} \tilde{c}^{F}\right] \frac{(p(t)-\tilde{p})}{\tilde{p}}-\tilde{p} \tilde{c}^{F} \frac{(c(t)-\tilde{c})}{\tilde{c}}
$$

Dividing by the initial steady-state GDP, denoting $\omega_{X}=\tilde{X} / \tilde{Y}, \tilde{p} \tilde{c}^{F} / \tilde{Y}=\frac{\tilde{p} \tilde{c}^{F}}{p_{c} \tilde{c}} \frac{p_{c} \tilde{c}}{\tilde{Y}}=\alpha_{c} \omega_{c}$, evaluating at time $t=0$ and differentiating yields:

$$
\frac{\tilde{p} \mathrm{~d} \dot{b}(0)}{\tilde{Y}}=\left[\omega_{X}\left(\eta_{X}-1\right)+\phi\left(1-\alpha_{c}\right) \omega_{c} \alpha_{c}\right] \frac{\mathrm{d} p(0)}{\tilde{p}}-\alpha_{c} \omega_{c} \frac{\mathrm{d} c(0)}{\tilde{c}} \lessgtr 0 .
$$

Eq. (81) corresponds to eq. (20) in the text.

The initial reaction of the current account measured in terms of the domestic good is given by:

$$
\frac{\mathrm{d} c a^{\prime}(0)}{\tilde{Y}}=\frac{\tilde{p} \mathrm{~d} \dot{b}(0)}{\tilde{Y}}+\frac{\tilde{p} \tilde{b}}{\tilde{Y}} \frac{\mathrm{d} \dot{p}(0)}{\tilde{p}}
$$

\section{A.6 The Case of a Small Open Economy}

Assuming that the economy is small in the world good markets so that it cannot longer influence the relative price of the domestic good $p$, the terms of trade turn out to be exogenous which greatly simplify the analysis of the effects of temporary fiscal shocks. The steady-state rewrites as: The steady-state is described by the following set of equations:

$$
\begin{gathered}
\tilde{c}=\left[\left(\frac{\beta+\sigma}{\beta+\sigma(1-\gamma)}\right) \frac{p_{c} \bar{\lambda}}{\tilde{p}}\right]^{-\nu} \\
\tilde{n}=\left(\frac{1}{\gamma_{N}} \frac{\bar{\lambda}}{\tilde{p}}\right)^{\sigma_{N}} \\
r^{\star} p \tilde{b}+\tilde{n}-p_{c} \tilde{c}-g=0
\end{gathered}
$$

where $\tilde{\Gamma}_{1}=-\frac{p_{c} \omega_{2}^{1}}{\mu_{1}-r^{\star}}>0$.

Now exports adjust at each instant of time to clear the home good market. The steadystate can be solved for consumption, labor and the stock of foreign bonds solve (41a)-(41b) for consumption and labor :

$$
\tilde{c}=c(\bar{\lambda}), \quad \tilde{n}=n(\bar{\lambda}), \quad \tilde{b}=b(\bar{\lambda}, g) .
$$

Consumption and labor doe no longer depend on government spending since the terms of trade are exogenous. Hence, a fiscal expansion exerts a negative influence on consumption and affects positively employment through the wealth effect. 
The zero current account expressed in percentage steady-state deviations reads as:

$$
\begin{aligned}
& \omega_{B} \hat{\tilde{b}}+\left(\sigma_{N}+\omega_{c} \nu\right) \hat{\bar{\lambda}}=\frac{\mathrm{d} g}{Y}, \\
& \hat{\tilde{b}}+\tilde{\Gamma}_{1} \tilde{\tilde{c}} \tilde{\tilde{b}} \nu \hat{\bar{\lambda}}=0 .
\end{aligned}
$$

The long-term change in the shadow value of wealth is given by:

$$
\frac{\hat{\bar{\lambda}}}{\frac{\mathrm{d} g}{Y}}=\frac{1}{\left(\sigma_{N}+\omega_{c} \nu\right)-\omega_{B} \tilde{\Gamma}_{1} \tilde{s}_{\hat{b}}^{\tilde{s}} \nu}>0 .
$$

Solving (56) yields:

$$
\begin{aligned}
\left.\frac{\mathrm{d} \bar{\lambda}}{\mathrm{d} g}\right|_{t e m p} & =\lambda_{g}\left(1-e^{-r^{\star} T}\right) \\
\frac{A_{1}}{\mathrm{~d} g} & =-\left.\frac{\mathrm{d} \tilde{c}_{1}}{\mathrm{~d} g}\right|_{t e m p}-\frac{A_{2}}{\mathrm{~d} g}=-\left.c_{\bar{\lambda}} \frac{\mathrm{d} \bar{\lambda}}{\mathrm{d} g}\right|_{t e m p} \\
\frac{A_{2}}{\mathrm{~d} g} & =0
\end{aligned}
$$

Setting $t=0$ into the formal solution for consumption and differentiating w.r.t. $g$ yields the initial jump of real consumption following an expansionary budget policy:

$$
\left.\frac{\mathrm{d} c(0) / \tilde{c}}{\mathrm{~d} g / \tilde{Y}}\right|_{t e m p}=\frac{\mu_{1}}{\sigma} \frac{\nu}{\sigma_{N}-\omega_{c} \nu \frac{\mu_{1}}{\sigma} \frac{\sigma+r^{\star}}{r^{\star}-\mu_{1}}}\left(1-e^{-r^{\star} T}\right),
$$

where we used the fact that $\frac{p_{c} \tilde{c}}{\tilde{Y}}=\omega_{c}$. Eq. (88) corresponds to eq. (17) in the text.

As stressed previously, in a small open economy model, the terms of trade are fixed so that $c_{g}=c_{p} p_{g}=0$ (since $p_{g}=0$ ). Using (70), the initial reaction of the current account rewrites as:

$$
c a(0)=-r^{\star} b_{g} e^{-r^{\star} T} \mathrm{~d} g+\mu_{1} \tilde{\Gamma}_{1} A_{1},
$$

where $A_{1}$ is given by (87b). Using the fact $\mathrm{d} c(0) / \tilde{c}=-\frac{\mu_{1}}{\sigma} \mathrm{d} \tilde{c} / \tilde{c}$ and $\hat{b}=\frac{1}{\omega_{B}} \frac{\mathrm{d} g}{\tilde{Y}}$, the initial reaction of the current account measured in domestic units and scaled by initial GDP reads:

$$
\left.\frac{\tilde{p} \mathrm{~d} c a(0)}{\tilde{Y}}\right|_{t e m p}=-\left.e^{-r^{\star} T} \frac{\mathrm{d} g}{Y}\right|_{t e m p}+\left.\omega_{c}\left(\frac{\sigma+\mu_{1}}{r^{\star}-\mu_{1}}\right) \frac{\mathrm{d} c(0)}{\tilde{c}}\right|_{t e m p},
$$

where $\left.\frac{\mathrm{d} c(0)}{\tilde{c}}\right|_{\text {temp }}$ is given by (88). Eq. (90) corresponds to eq. (19) in the text. 